\title{
Study of oxidation states of the transition metals in a series of Prussian Blue Analogs using X-ray absorption near edge structure (XANES) spectroscopy
}

\author{
S. Adak', M. Hartl' ${ }^{2,4}$, L. Daemen ${ }^{3,4}$, E. Fohtung ${ }^{1}$, and H. Nakotte ${ }^{1}$ \\ ${ }^{1}$ Department of Physics, New Mexico State University, Las Cruces, NM 88003, USA \\ ${ }^{2}$ European Spallation Source ESS AB, 22100 Lund, Sweden \\ ${ }^{3}$ Spallation Neutron Source, Oak Ridge National Laboratory, Oak Ridge, TN 37830, \\ USA \\ ${ }^{4}$ Manuel Lujan Jr. Neutron Scattering Center (LANSCE-LC), Los Alamos National \\ Laboratory, Los Alamos, NM 87545, USA
}

\begin{abstract}
There have been renewed interests in metal-organic framework classes of materials such as prussian blue analogues (PBAs) due to their potential usage in energy storage applications. In particular, due to their high surface areas, controllable structures and excellent electrochemical properties, PBAs such as hexacyanometalates $M_{3}^{\prime \prime}\left[A^{\prime \prime \prime}(C N)_{6}\right]_{2} * H_{2} \mathrm{O}(\mathrm{M}=\mathrm{Mn}, \mathrm{Fe}, \mathrm{Co}, \mathrm{Ni}, \mathrm{Cu}, \mathrm{Zn} ; \mathrm{A}=\mathrm{Co}, \mathrm{Fe}, \mathrm{Cr} ; n=$ no. of water molecules present), $\mathrm{M}_{2}^{\prime \prime}\left[\mathrm{Fe}^{\prime \prime}(\mathrm{CN})_{6}\right]_{2} \times \mathrm{H}_{2} \mathrm{O}(\mathrm{M}=\mathrm{Mn}, \mathrm{Co}, \mathrm{Ni}, \mathrm{Cu}, \mathrm{Zn})$ and mixed hexacyanometalates(III) $\left(\mathrm{Fe}_{1-x} \mathrm{Co}_{x}\right)_{3}\left[\mathrm{~B}^{\prime \prime \prime}(\mathrm{CN})_{6}\right]_{2} . n \mathrm{H}_{2} \mathrm{O}(\mathrm{x}=0.25,0.5,0.75 ; \mathrm{B}=\mathrm{Co}$, Fe) could have possible usage as a new class of cathode and even anode materials for rechargeable batteries. Detailed knowledge of the oxidation states of the transition metals in PBAs is required to improve efficiency and durability of such devices. Furthermore, a link between the thermal expansion observed in these materials and the oxidation state of the transition metal is of interest to synthesize materials with a desired thermal expansion behavior, Here we demonstrate the use of Synchrotron based X-ray absorption near-edge structure (XANES) spectra to identify transition metal oxidation states. Our analysis reveals the presence of divalent, trivalent and/or mixed valence transition metals in the materials as well as high-spin and low-spin complexes.
\end{abstract}

Keywords: XANES, oxidation states, Prussian Blue Analogs, hexacyanometallates 


\section{Introduction}

Prussian blue (PB) analogs have gained renewed interest recently because of their interesting characteristics as molecular magnets and their technologically important response to external stimuli, e.g., photo-excitation, hydrostatic pressure and reduced pressure etc. Moreover, some of the PB analogs have been found to exhibit counterintuitive negative thermal expansion (NTE) behavior and near-zero thermal expansion (ZTE) behavior both of which are of fundamental as well as of great technological importance. For example, Matsuda et al. ${ }^{1}$ reported the occurrence of NTE in a few PB analogs while Chapman et al. ${ }^{2}$ demonstrated the compositional dependence of the NTE behavior in some other PB analogs. Since it is possible to vary systematically the charge and ion size in these materials, PB analogs offer an interesting platform to explore possible correlation between NTE and electronic structure.

In a previous study, ${ }^{3}$ our group reported the thermal expansion behavior of PB analog compounds. Our study indicates some of the compounds hexacyanocobaltates(III) of $\mathrm{Mn}, \mathrm{Fe}, \mathrm{Co}, \mathrm{Ni}, \mathrm{Cu}$, and $\mathrm{Zn}$, hexacyanoferrates (III) of $\mathrm{Co}, \mathrm{Cu}, \mathrm{Zn}$, and hexacynochromate (III) of Fe - show NTE behavior in the temperature range $300-123 \mathrm{~K}$ while the other compounds show either positive thermal expansion (PTE) behavior or complex NTE/PTE behavior. Simple parameters such as formal charge, ionic radius, electronegativity, or magnetic moments fail to correlate in any obvious way with the thermal expansion behavior of PBs. The presence of rigid unit modes (RUMs) remains a plausible explanation of the variety of thermal expansion behaviors in PBs providing the forces between octahedra mediated by the cyanide ligands varied from sample to sample. These forces are a consequence of chemical bonding, and, therefore, of the distribution of electronic density on the metal ion (oxidation state) and among the octahedra. Another contributing factor may be cyanide ligand disorder. A quick way to investigate these possibilities (electron distribution and ligand disorder) is to perform XANES measurements to determine formal charges on the metal cations and, possibly, some local structure information (ligand orientation). Although EXAFS and XANES studies of other PB analogs have been reported, ${ }^{4,5}$ results are missing for most of our compounds, particularly those displaying complex thermal expansion 
behavior. Previous synchrotron $\mathrm{x}$-ray studies focused largely on electronic band structure, photoemission, and optical properties. We were unable to find any study devoted to oxidation states in our series of PB compounds. Hence, characterizing the formal oxidations states of the transition metals present in the studied series of Prussian blue analogs remains important.

In the present study, we used XANES to characterize the oxidation states of the transition metals in the PB analogs, at the $\mathrm{Cr}, \mathrm{Mn}, \mathrm{Fe}, \mathrm{Co}, \mathrm{Ni}$ and $\mathrm{Cu}$ K-edge in a systematic way.

\section{MATERIALS AND EXPERIMENTAL METHODS}

\subsection{Materials}

\subsubsection{Synthesis}

Table I summarizes the list of materials investigated in this study. The compounds are synthesized via standard chemical precipitation using ACS quality reagents.

Hexacyanocobaltates(III) of the divalent metals $\mathrm{Mn}, \mathrm{Fe}, \mathrm{Co}, \mathrm{Ni}, \mathrm{Cu}$ and $\mathrm{Zn}$ were prepared by mixing the aqueous solutions of stoichiometric amounts of metal chloride or nitrate with the aqueous solution of $\mathrm{K}_{3}\left[\mathrm{Co}(\mathrm{CN})_{6}\right]$. The precipitated sample was filtered, washed multiple times with water, and air dried. Polycrystalline samples of hexacyanoferrates(III), hexacyanoferrates(II) and hexacyanohromates(III) were synthesized following the same synthesis route using $\mathrm{K}_{3}\left[\mathrm{Fe}(\mathrm{CN})_{6}\right], \mathrm{K}_{4}\left[\mathrm{Fe}(\mathrm{CN})_{6}\right]$ and $\mathrm{K}_{3}\left[\mathrm{Cr}(\mathrm{CN})_{6}\right]$, respectively.

Bimetallic hexacyanoferrates(III) and hexacyanocobaltates(III) were synthesized by mixing a combined solution of aqueous solutions of $\mathrm{FeCl}_{2}$ and $\mathrm{CoCl}_{2}$, prepared using the calculated stoichiometric amounts needed for a particular $x$-value, with aqueous solution of $\mathrm{K}_{3}\left[\mathrm{Fe}(\mathrm{CN})_{6}\right]$ and $\mathrm{K}_{3}\left[\mathrm{Co}(\mathrm{CN})_{6}\right]$ respectively. Powder samples were obtained following the same procedure as mentioned earlier. 
TABLE I. List of compounds, space groups and room temperature lattice parameters a and coefficient $\alpha$ of thermal expansion for all studied compounds. *already published ${ }^{3}$

\begin{tabular}{|c|c|c|c|c|}
\hline Sample & PB analogs & $\begin{array}{l}\text { Space } \\
\text { group }\end{array}$ & $a[\AA]$ & $\alpha\left[10^{-6} \mathrm{~K}^{-1}\right]$ \\
\hline & $\begin{array}{l}\text { Metal(II) Hexacyanocobaltates } \\
\text { (III) }\end{array}$ & & & \\
\hline$(a)^{*}$ & $\mathrm{Mn}_{3}\left[\mathrm{Co}(\mathrm{CN})_{6}\right]_{2 .} .12 \mathrm{H}_{2} \mathrm{O}$ & $F \overline{4} 3 m$ & $10.3327(5)$ & $-48.0(2.5)$ \\
\hline$(b)^{*}$ & $\mathrm{Fe}_{3}\left[\mathrm{Co}(\mathrm{CN})_{6}\right]_{2} \cdot 28 \mathrm{H}_{2} \mathrm{O}$ & $\bar{F} \overline{4} 3 m$ & $10.2241(12)$ & $-39.3(6.0)$ \\
\hline$(\mathrm{c})^{*}$ & 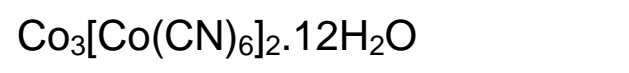 & $F \overline{4} 3 m$ & $10.1277(18)$ & $-35.5(5.1)$ \\
\hline$(d)^{*}$ & $\mathrm{Ni}_{3}\left[\mathrm{Co}(\mathrm{CN})_{6}\right]_{2 .} 16 \mathrm{H}_{2} \mathrm{O}$ & $F \overline{4} 3 m$ & $10.0532(14)$ & $-30.0(4.4)$ \\
\hline$(e)^{*}$ & $\mathrm{Cu}_{3}\left[\mathrm{Co}(\mathrm{CN})_{6}\right]_{2 .} .17 \mathrm{H}_{2} \mathrm{O}$ & $F m \overline{3} m$ & $09.9964(7)$ & $-20.0(1.2)$ \\
\hline \multirow[t]{2}{*}{$(f)^{*}$} & $\mathrm{Zn}_{3}\left[\mathrm{Co}(\mathrm{CN})_{6}\right]_{2} .9 \mathrm{H}_{2} \mathrm{O}$ & $F \overline{4} 3 m$ & $10.1437(10)$ & $-33.7(2.6)$ \\
\hline & Metal(II) Hexacyanoferrates (III) & & & \\
\hline$(g)^{*}$ & $\mathrm{Mn}_{3}\left[\mathrm{Fe}(\mathrm{CN})_{6}\right]_{2 .} \cdot 14 \mathrm{H}_{2} \mathrm{O}$ & $F \overline{4} 3 m$ & $10.3218(13)$ & $+47.8(3.4)$ \\
\hline$(h)^{*}$ & $\mathrm{Co}_{3}\left[\mathrm{Fe}(\mathrm{CN})_{6}\right]_{2 .} \cdot 18 \mathrm{H}_{2} \mathrm{O}$ & $F \overline{4} 3 m$ & $10.0616(14)$ & $+7.9(5.1)$ \\
\hline$(i)^{*}$ & $\mathrm{Ni}_{3}\left[\mathrm{Fe}(\mathrm{CN})_{6}\right]_{2 \cdot} \cdot 14 \mathrm{H}_{2} \mathrm{O}$ & $F \overline{4} 3 m$ & $10.1834(12)$ & $+5.9(1.9)$ \\
\hline$(j)^{*}$ & $\mathrm{Cu}_{3}\left[\mathrm{Fe}(\mathrm{CN})_{6}\right]_{2 .} .18 \mathrm{H}_{2} \mathrm{O}$ & $F m \overline{3} m$ & $10.0635(6)$ & $-19.9(0.6)$ \\
\hline \multirow[t]{2}{*}{$(k)^{*}$} & $\mathrm{Zn}_{3}\left[\mathrm{Fe}(\mathrm{CN})_{6}\right]_{2 .} .14 \mathrm{H}_{2} \mathrm{O}$ & $F m \overline{3} m$ & $10.1615(15)$ & $-39.6(6.2)$ \\
\hline & $\begin{array}{l}\text { Metal(II) Hexacyanochromates } \\
\text { (III) }\end{array}$ & & & \\
\hline (l) & $\mathrm{Fe}_{3}\left[\mathrm{Cr}(\mathrm{CN})_{6}\right]_{2} \cdot 10 \mathrm{H}_{2} \mathrm{O}$ & $F m \overline{3} m$ & $10.1623(8)$ & -4.92 \\
\hline (m) & $\mathrm{Co}_{3}\left[\mathrm{Cr}(\mathrm{CN})_{6}\right]_{2} \cdot 14 \mathrm{H}_{2} \mathrm{O}$ & $F m \overline{3} m$ & $10.1412(15)$ & +59.16 \\
\hline (n) & $\mathrm{Ni}_{3}\left[\mathrm{Cr}(\mathrm{CN})_{6}\right]_{2} \cdot 14 \mathrm{H}_{2} \mathrm{O}$ & $F m \overline{3} m$ & $9.9503(24)$ & +10.05 \\
\hline$(0)^{*}$ & $\begin{array}{l}\text { Metal(II) Hexacyanoferrates (II) } \\
\mathrm{Mn}_{2}\left[\mathrm{Fe}(\mathrm{CN})_{6}\right] \cdot 9 \mathrm{H}_{2} \mathrm{O}\end{array}$ & $\begin{array}{l}\text { P } 121 / n \\
1\end{array}$ & $9.9254(21)$ & $+20.2(5.0)$ \\
\hline & & & & \\
\hline
\end{tabular}




\begin{tabular}{|c|c|c|c|c|}
\hline$(p)^{*}$ & $\mathrm{Co}_{2}\left[\mathrm{Fe}(\mathrm{CN})_{6}\right] \cdot 18 \mathrm{H}_{2} \mathrm{O}$ & $P m \overline{3} m$ & $10.2269(9)$ & $+19.5(10.7)$ \\
\hline$(q)^{*}$ & $\mathrm{Ni}_{2}\left[\mathrm{Fe}(\mathrm{CN})_{6}\right] .18 \mathrm{H}_{2} \mathrm{O}$ & $P m \overline{3} m$ & $10.0383(19)$ & $+19.9(3.0)$ \\
\hline$(r)^{\prime}$ & $\mathrm{Cu}_{2}\left[\mathrm{Fe}(\mathrm{CN})_{6}\right] \cdot 16 \mathrm{H}_{2} \mathrm{O}$ & $P m \overline{3} m$ & $9.9321(6)$ & $+20.1(9.7)$ \\
\hline \multirow[t]{2}{*}{$(s)^{*}$} & $\mathrm{Zn}_{2}\left[\mathrm{Fe}(\mathrm{CN})_{6}\right] \cdot 5 \mathrm{H}_{2} \mathrm{O}$ & $P \overline{3}$ & $6.9172(20)$ & $+43.1(2.7)$ \\
\hline & $\begin{array}{l}\text { Bimetallic Hexacyanocobaltates } \\
\text { (III) }\end{array}$ & & & \\
\hline$(\mathrm{t})$ & $\left(\mathrm{Fe}_{0.75} \mathrm{Co}_{0.25}\right)_{3}\left[\mathrm{Co}(\mathrm{CN})_{6}\right]_{2 \cdot} \cdot x \mathrm{H}_{2} \mathrm{O}$ & $F \overline{4} 3 m$ & $10.1829(11)$ & -19.53 \\
\hline (u) & $\left(\mathrm{Fe}_{0.50} \mathrm{Co}_{0.50}\right)_{3}\left[\mathrm{Co}(\mathrm{CN})_{6}\right]_{2 .} \times \mathrm{H}_{2} \mathrm{O}$ & $F \overline{4} 3 m$ & $10.2279(14)$ & -0.29 \\
\hline (v) & $\left(\mathrm{Fe}_{0.25} \mathrm{Co}_{0.75}\right)_{3}\left[\mathrm{Co}(\mathrm{CN})_{6}\right]_{2 \cdot} \cdot x \mathrm{H}_{2} \mathrm{O}$ & $F \overline{4} 3 m$ & $10.2469(20)$ & -19.42 \\
\hline & Bimetallic Hexacyanoferrates (I & & & \\
\hline$(w)$ & $\left(\mathrm{Fe}_{0.75} \mathrm{Co}_{0.25}\right)_{3}\left[\mathrm{Fe}(\mathrm{CN})_{6}\right]_{2 .} . x \mathrm{H}_{2} \mathrm{O}$ & $F m \overline{3} m$ & $10.0250(22)$ & +10.00 \\
\hline$(x)$ & $\left(\mathrm{Fe}_{0.50} \mathrm{Co}_{0.50}\right)_{3}\left[\mathrm{Fe}(\mathrm{CN})_{6}\right]_{2} . x \mathrm{H}_{2} \mathrm{O}$ & $F m \overline{3} m$ & $10.0067(16)$ & -5.98 \\
\hline$(y)$ & $\left(\mathrm{Fe}_{0.25} \mathrm{Co}_{0.75}\right)_{3}\left[\mathrm{Fe}(\mathrm{CN})_{6}\right]_{2 \cdot} \cdot x \mathrm{H}_{2} \mathrm{O}$ & $F m \overline{3} m$ & $10.0898(12)$ & 1.98 \\
\hline
\end{tabular}

\subsubsection{Structure of Materials}

Most of the studied PBAs crystallize in the cubic space groups $F m \overline{3} m, F \overline{4} 3 m$ or $\mathrm{Pm}_{\overline{3}} \mathrm{~m}$ (Figures 1a-c). $\mathrm{Mn}_{2}\left[\mathrm{Fe}(\mathrm{CN})_{6}\right] .9 \mathrm{H}_{2} \mathrm{O}$ and $\mathrm{Zn}_{2}\left[\mathrm{Fe}(\mathrm{CN})_{6}\right] .5 \mathrm{H}_{2} \mathrm{O}$, on the other hand, crystallize in the monoclinic $P 2_{1} / n$ and trigonal $P \overline{3}$ space groups (not shown in Figure 1), respectively, which are distortions of the cubic structures. All structures invariably consist of two types of octahedra, $M(N \equiv C)_{6}$ and $M^{\prime}(C \equiv N)_{6}$, arranged in an essentially cubic lattice with cyanide ligands linking the metal centers. Each metal has a coordination number of 6 . In the above notation for the octrahedra, we neglected the possibility of $O$ atoms replacing " $C$ " or " $N$ " since the oxygen atom of the water molecules may occupy those regular lattice positions in order to complete the octahedra. In $F m \overline{3} m$ and $F \overline{4} 3 m$ type PBAs, the $O$ occupancy of such regular positions occurs essentially randomly at defect sites; however, for $P m \overline{3} m$ type PBAs, 
the octahedra of the divalent metal ion $M^{\prime \prime}(N \equiv C)_{3}\left(\mathrm{OH}_{2}\right)_{3}$ the cyanide ligand is replace by up to three water molecules.

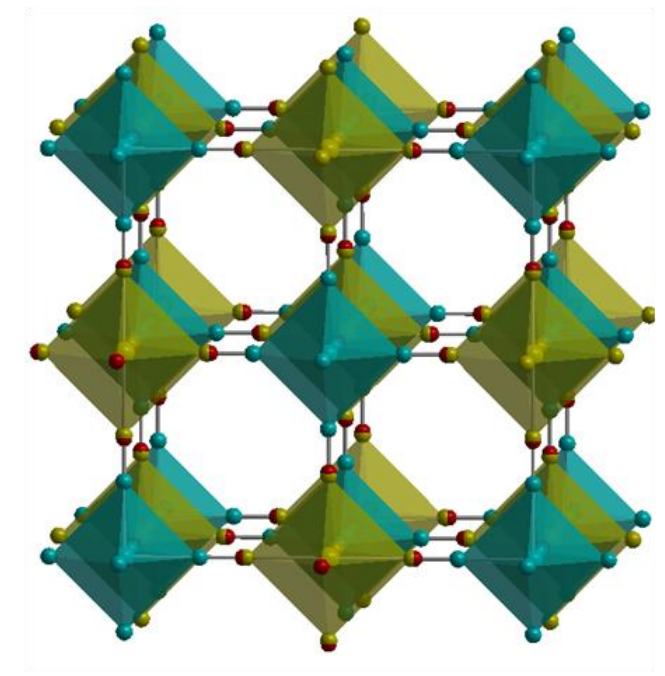

a) Space group: $F m \overline{3} m$

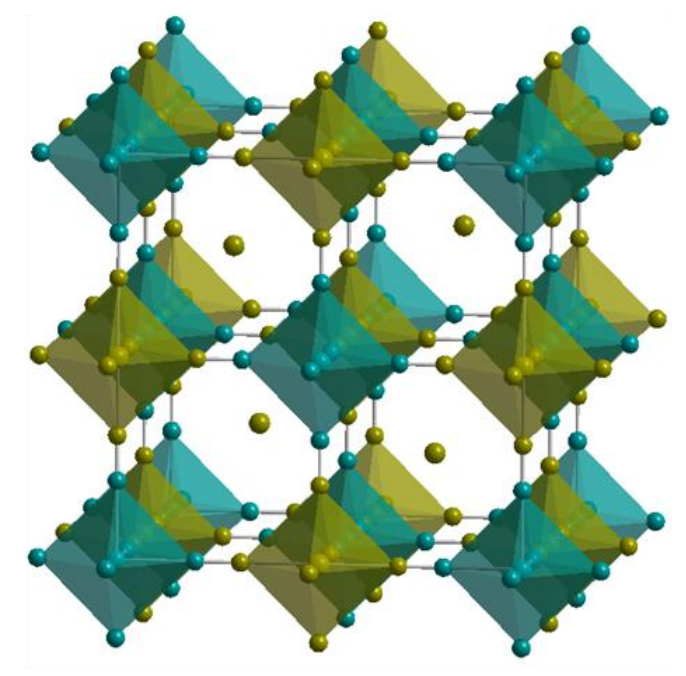

b) Space group: $F \overline{4} 3 m$

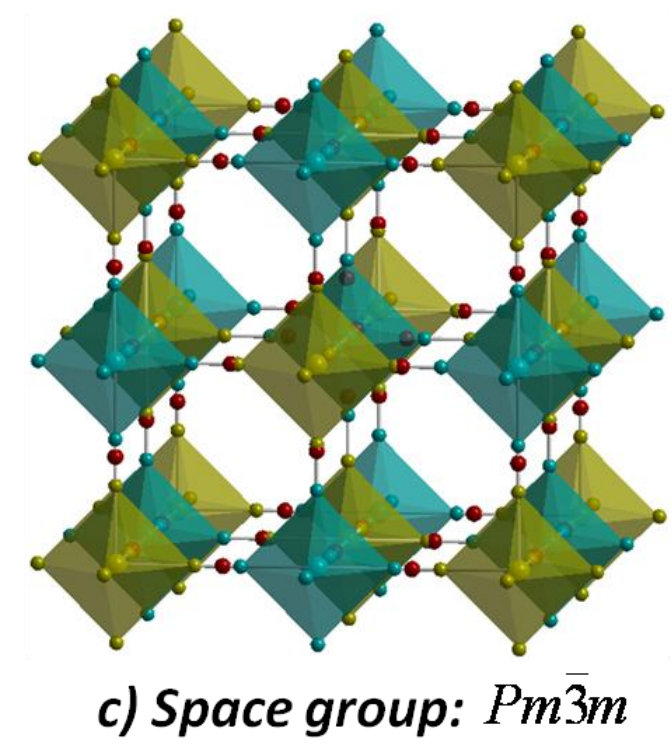

FIG. 1. Sketch of crystal structure of Prussian Blue analog $\mathrm{Fe}_{3}^{\prime \prime}\left[\mathrm{Co}^{\prime \prime \prime}(\mathrm{CN})_{6}\right]_{2} \times \mathrm{H}_{2} \mathrm{O}$ indicating " $\mathrm{FeN}_{6}$ " (green) and " $\mathrm{CoC}_{6}$ " (yellow) octahedra separating the metal centers by linear cyanide ligands. Not all octahedra in the structure are complete. Water molecules are present in lattice as well as in interstitial positions between the octahedra.

\subsection{X-ray Absorption Near Edge Spectroscopic Measurements}

$\mathrm{Cr}, \mathrm{Mn}, \mathrm{Fe}, \mathrm{Co}, \mathrm{Ni}$, and $\mathrm{Cu} \mathrm{K}$-edge XANES spectra for the studied Prussian Blue analogs (PBAs) and reference samples were collected in the transmission mode at the 9-BM-B beamline of Advanced Photon Source, Argonne National Laboratory 
which is operated in the energy range 2.1 - $23 \mathrm{keV}$. Double crystals of Si (111) were used as monochromator without focusing. Higher order harmonics were rejected by detuning the double crystal by $\sim 60-80 \%$ of the intensity. Ionization chambers filled with pure $\mathrm{N}_{2}$ were used to measure the incident and transmitted x-ray intensities. The respective metal foils were recorded simultaneously as energy standard using a third ionization chamber filled with pure $\mathrm{N}_{2}$. For most of our samples pellets of appropriate thickness were pressed with powder samples diluted with ethylene oxide. For a few samples measurements were done with powdered samples mixed with ethylene oxide on tape.

All the XANES data are analyzed using the WinXAS software ${ }^{6}$ following the standard analysis procedure - energy calibration, background correction and normalization. Sample XANES spectra were compared with the reference XANES spectra in order to determine the oxidation states of the metal cations in the PB analogs.

\subsection{X-ray Diffraction Measurements}

X-ray diffraction patterns were collected on an Rigaku Ultima III X-ray diffractometer using a $\mathrm{Cu} \mathrm{K \alpha}$ source in the range of $2 \Theta=10-90^{\circ}$. The step size was $0.04^{\circ}$ and the scan speed was $2 \% / \mathrm{min}$. The samples were loaded on a copper sample holder and the diffractometer operated in Bragg-Brentano geometry. The lattice parameters were refined using the Rietveld refinement program package GSAS. ${ }^{41}$ The coefficients of thermal expansion were determined as described elsewhere. ${ }^{3}$

\section{Results and Discussion}

XANES spectra contain characteristic features which provide useful information about the local symmetry, coordination environment and structure of the scattering atom, as well as the formal oxidation state of the target atom. For easier discussions we have split the XANES spectra in three parts. Part A includes the pre-edge features, part $B$ is the edge itself and part $C$ is the region right after the edge that contains multiple-scattering. We will do that for all XANES spectra in this paper to be able to better interpret and compare the spectra. In the following section the spectra are sorted by the X-ray absorption edge. 


\subsection{Cr $K$-edge XANES}

Figure 2 shows the normalized $\mathrm{Cr} K$-edge XANES spectra for the three hexacyanochromate(III) compounds, $\mathrm{Fe}{ }_{3}\left[\mathrm{Cr}(\mathrm{CN})_{6}\right]_{2}, \mathrm{Co}_{3}\left[\mathrm{Cr}(\mathrm{CN})_{6}\right]_{2}, \mathrm{Ni}_{3}\left[\mathrm{Cr}(\mathrm{CN})_{6}\right]$ (Table I, (I)-(n)) along with the reference compounds $\mathrm{Cr}_{2} \mathrm{O}_{3}$ and $\mathrm{K}_{2}\left[\mathrm{Cr}_{2} \mathrm{O}_{7}\right]$ with $\mathrm{Cr}$ oxidation states III and $\mathrm{VI}$, respectively. The energy scale in the figure is relative to the $\mathrm{Cr} K$-edge in chromium metal at $5.989 \mathrm{keV}$.
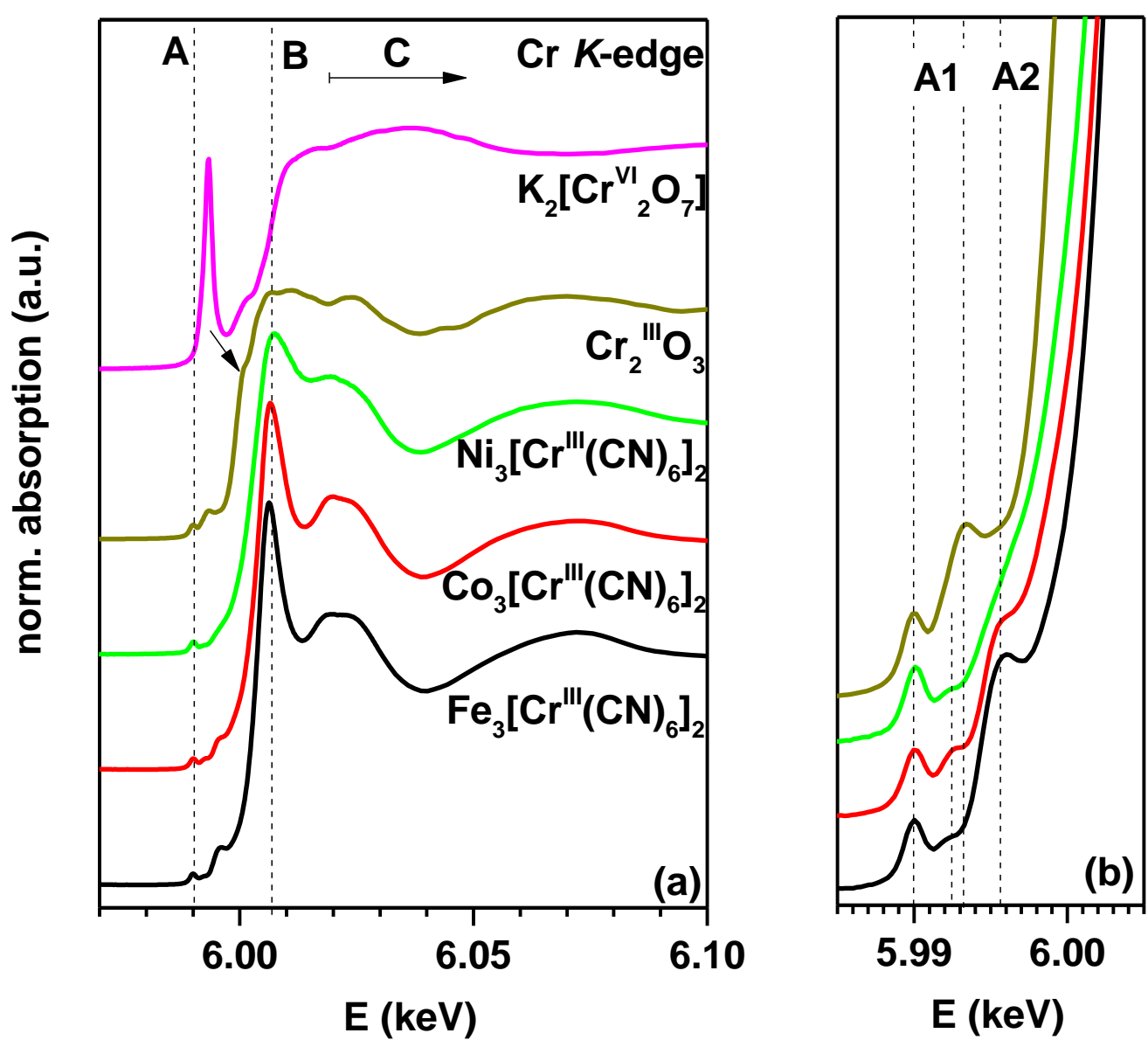

FIG. 2. Cr K-edge XANES spectra for the metal(II) hexacyanochromate(III) samples $\mathrm{M}_{3}{ }_{3}\left[\mathrm{Cr}^{\mathrm{III}}(\mathrm{CN})_{6}\right]_{2},(\mathrm{I})-(\mathrm{n})$, and the reference compounds $\mathrm{Cr}_{2} \mathrm{O}_{3}$ and $\mathrm{K}_{2} \mathrm{Cr}_{2} \mathrm{O}_{7}$ : (a) XANES spectra showing a dotted line $A$ in the pre-edge region and a dotted line indicating the maximum after the edge (B). The arrow indicates a $1 s \rightarrow 4 p$ dipole-allowed transition present in the samples as well as the reference compound $\mathrm{Cr}_{2} \mathrm{O}_{3}$; (b) details of the pre-edge region. The energy scale is relative to the $\mathrm{Cr}$ K-edge in chromium metal (5.9890 keV).

The last edge contribution before the first absorption maximum of the edge is chosen as the main edge (B). As can be seen in figure 2, the edge positions (B) in all 
the sample spectra agree with the edge position of $\mathrm{Cr}_{2} \mathrm{O}_{3}$ at $6.0033 \mathrm{keV}$ indicating the presence of $\mathrm{Cr}(\mathrm{III})$ ions in the samples. It is hard to determine the oxidation state of chromium by the edge position alone since the geometry of the ligands surrounding the chromium has a significant influence on the shape of the edge. ${ }^{10} \mathrm{~A}$ detailed analysis of all edge features as given below is necessary to assure the identification of the main edge is correct.

The pre-edge (A1) of $\mathrm{Cr}_{2} \mathrm{O}_{3}$ contains two peaks at 5.990 and $5.993 \mathrm{keV}$ corresponding to the dipole-forbidden transition $1 s \rightarrow 3 d\left(t_{2 \mathrm{~g}}\right.$ and $\left.e_{g}\right){ }^{7} \mathrm{Cr}_{2} \mathrm{O}_{3}$ crystallizes in the corundum $\left(\mathrm{Al}_{2} \mathrm{O}_{3}\right)$ structure with $\mathrm{Cr}$ being the center of distorted oxygen octahedra. Due to the distortion of the octahedra, the law that forbids the $1 s \rightarrow 3 d$ transition is partially invalidated and intensity is visible in the spectrum. The ligand-field splitting as observed by optical data ${ }^{8}$ into $t_{2 g}$ and $e_{g}$ shows a splitting of $2.8 \mathrm{eV}$ which agrees well with the difference in pre-edge peak position of $3 \mathrm{eV}$ observed here. This feature can be also seen in the spectra of the $\mathrm{Fe}, \mathrm{Co}$ and $\mathrm{Ni}$ hexacyanochromate(III) albeit with very little intensity and shifted to $5.992 \mathrm{keV}$. The presence of this feature in the samples implies that the $\mathrm{Cr}$ (III) ions are in a distorted octahedral surrounding with a smaller ligand-field splitting. The XANES spectrum of $\mathrm{K}_{2} \mathrm{Cr}_{2} \mathrm{O}_{7}$ has an intense pre-edge feature at $5.993 \mathrm{keV}$ (Figure $2 \mathrm{a}$ ). Since $\mathrm{Cr}$ in $\mathrm{K}_{2} \mathrm{Cr}_{2} \mathrm{O}_{7}$ is surrounded tetrahedrally by oxygen and therefore does not sit in an inversion center, the $1 s \rightarrow 3 d$ transition is allowed and the peak is intense. In addition to the two small resonance peaks, there is also a shoulder (A2) in the preedge region at $5.996 \mathrm{keV}$. It can be observed in the Fe and Co samples and might be present in the Ni sample but significantly broadened. This feature has also been observed by other researchers in chromium compounds ${ }^{9}$ and is very likely due to a $1 s \rightarrow 4 p$ dipole-allowed transition. This transition is also observable in the $\mathrm{Cr}_{2} \mathrm{O}_{3}$ spectrum but very close to the edge at $6.000 \mathrm{keV}$ (see arrow in figure 2(a)).

The region $(\mathrm{C})$ after the edge is very similar for all three samples and comparable to what has been observed in other metalhexacyano complexes. ${ }^{11,12}$ This is the area of the XANES spectrum where multiple scattering is observed that strongly depends on the geometry and symmetry of the nearest neighbors of the absorber, in this case the "Cr(CN)6" entity.

The spectral features of all three sample spectra are similar which indicates that the $\mathrm{Cr}$ atoms in all three samples have similar electronic and structural 
environments. Cr KXANES proves that $\mathrm{Cr}$ is in oxidation state (III) in all three hexacyanochromates(III) in distorted octahedral surrounding.

\subsection{Mn K-edge XANES}

The Mn K-edge XANES signatures of the manganese(II) hexacyanometallates $\mathrm{Mn}_{3}\left[\mathrm{Co}(\mathrm{CN})_{6}\right]_{2}, \mathrm{Mn}_{3}\left[\mathrm{Fe}(\mathrm{CN})_{6}\right]_{2}$ and $\mathrm{Mn}_{2}\left[\mathrm{Fe}(\mathrm{CN})_{6}\right]($ Table I, (a), (g),(o)) and that of the reference compounds $\mathrm{MnO}, \mathrm{Mn}_{2} \mathrm{O}_{3}$, and $\mathrm{MnO}_{2}$ with manganese in the oxidation state (II), (III) and (IV), respectively, are displayed in Figure 3. The energy scale shown in the spectra is relative to the $\mathrm{Mn} K$-edge in manganese metal at $6.539 \mathrm{keV}$.
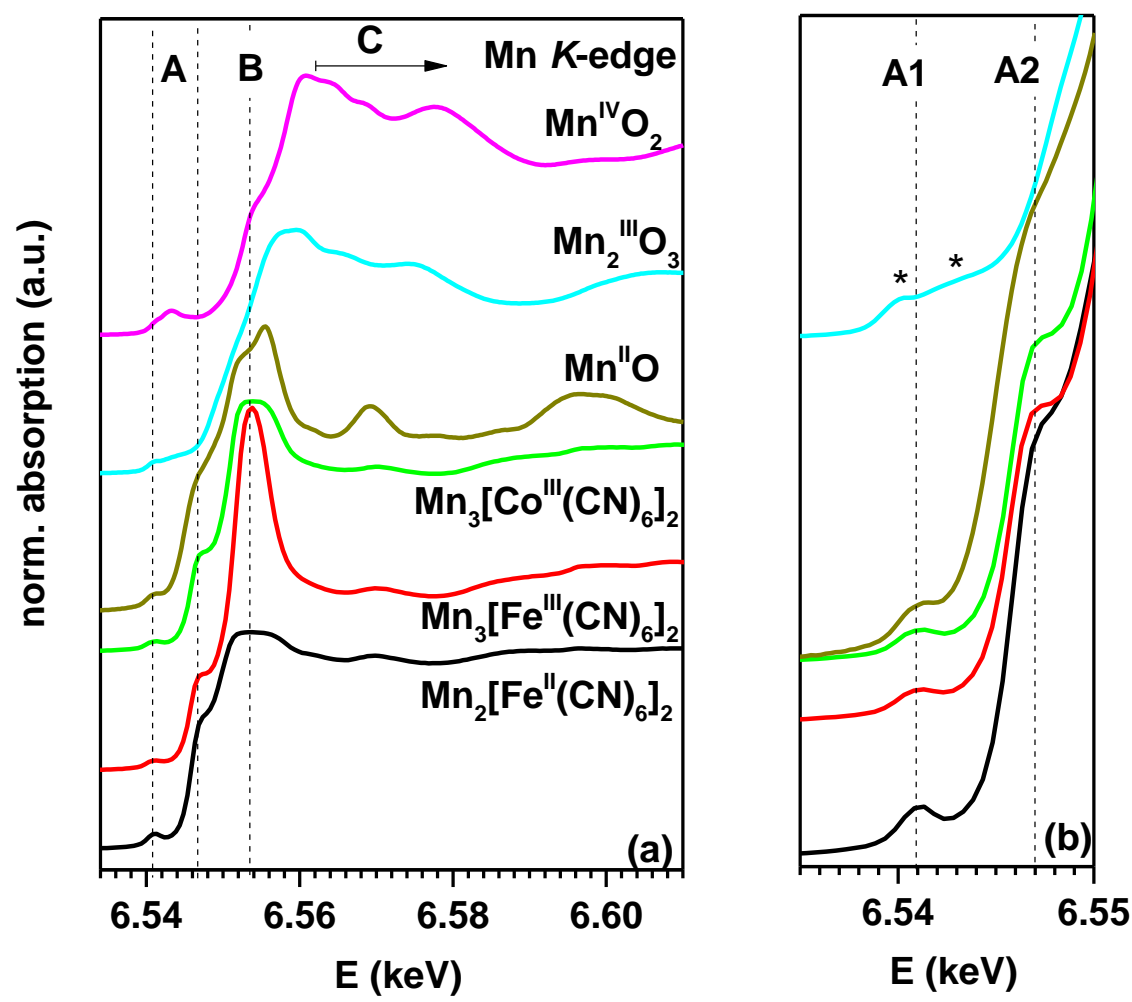

FIG. 3. Mn K-edge XANES spectra for compounds $\mathrm{Mn}_{3}\left[\mathrm{Co}^{\prime \prime \prime}(\mathrm{CN})_{6}\right]_{2}(\mathrm{a}), \mathrm{Mn}_{3}\left[\mathrm{Fe}^{\prime \prime \prime}(\mathrm{CN})_{6}\right]_{2}(\mathrm{~g})$, $\mathrm{Mn}_{2}\left[\mathrm{Fe}^{\prime \prime}(\mathrm{CN})_{6}\right](0)$, and references: (a) main XANES spectra (the dotted line between $A$ and $B$ shows the matching of the edge position $6.5448 \mathrm{keV}$, as determined from the inflection point, of the samples with that of reference compound $\mathrm{MnO}$ ); (b) detail of the pre-edge region (A). The asterisk marks two pre-edge features of $\mathrm{Mn}_{2} \mathrm{O}_{3}$. The energy scale is relative to the $\mathrm{Mn} K$-edge in metal $(6.5400 \mathrm{keV})$. 
Comparison of the sample spectra with the reference spectra indicates that all the edge positions in the sample spectra are close to the Mn K-edge XANES spectra for $\mathrm{Mn}$ "O. Again the edge position is affected by the medium to long-range environment caused by the ligands, while the pre-edge features are much less affected ${ }^{13}$.

In the structure of $\mathrm{MnO}, \mathrm{Mn}$ (II) occupies a centrosymmetric site and is octahedrally ( $O_{h}$ point group) coordinated with oxygen atoms. The pre-edge feature (A1) exhibits a doublet hidden underneath a broad feature at $6.541 \mathrm{keV}$ (Fig. 3 (b)) which is assigned to the electronic transitions from $1 s$ state to the crystal-field-split $3 d$ states $\left(3 d t_{2 g}\right.$ and $\left.3 d e_{g}\right) .{ }^{13,14}$ The polarized resonant inelastic $x$-ray scattering RIXS experiments performed at the $\mathrm{Mn} K$ edge on a single crystal of $\mathrm{MnO}$ provides evidence for the occurrence of the doublet ${ }^{14,15}$ with a difference of the $3 d t_{2 g}$ and $3 d e_{g}$ states of $0.8 \mathrm{keV}$ too small to be resolved in our measurements. This pre-edge feature is also found in the spectra of our samples albeit broader due to the crystal field splitting caused by the strong ligand "CN", where the $\mathrm{Mn}$ atoms are octahedrally coordinated with six nitrogen atoms. The lattice sites of the six nitrogen atoms can be shared partially by the oxygen atoms from the lattice water present in the samples leading to a distorted octahedral surrounding. The pre-edge region in the manganese(II) hexacyanometallate spectra differs significantly from the spectrum of $\mathrm{Mn}_{2}{ }_{2} \mathrm{O}_{3}$. There we observe two features marked with asterisks in Figure $3(\mathrm{~b})$ at lower and higher energies than for our samples and $\mathrm{MnO} .{ }^{13} \mathrm{~A}$ second feature in the pre-edge region (A2) at 6.547 is caused by the $1 s \rightarrow 4 p$ dipole-allowed transition and present in all manganese hexacyanometallate spectra and $\mathrm{Mn}$ "O.

The last edge contribution before the first absorption maximum of the edge is chosen as the main edge (B) and is assigned to the first inflection point in the spectra right after the pre-edge region. The main edge position is at $6.545 \mathrm{keV}$ for the model compound $\mathrm{Mn}$ "O. The main edge appears at the same position for the samples indicating the presence of divalent $\mathrm{Mn}$ in all samples. The post-edge regions $(C)$ of the sample spectra look very similar to each other and show hardly any features indicating a fairly disordered local surrounding of the manganese atoms. 


\subsection{Fe K-edge XANES}

\subsubsection{Metal Hexacyanoferrates(III)}

The Fe $K$-edge XANES spectra for the metal(II) hexacyanoferrates(III), (Table I, $(\mathrm{g})-(\mathrm{k}))$, and the reference compounds $\mathrm{K}_{4}\left[\mathrm{Fe}^{\prime \prime}(\mathrm{CN})_{6}\right]$ and $\mathrm{K}_{3}\left[\mathrm{Fe}^{\prime \prime \prime}(\mathrm{CN})_{6}\right]$ are shown in Figure 4. The spectra of all hexayanoferrate(III) samples resemble closely that of $\mathrm{K}$ ${ }_{3}\left[\mathrm{Fe}{ }^{\prime \prime \prime}(\mathrm{CN})_{6}\right]$ implying the presence of trivalent $\mathrm{Fe}$ in the samples.
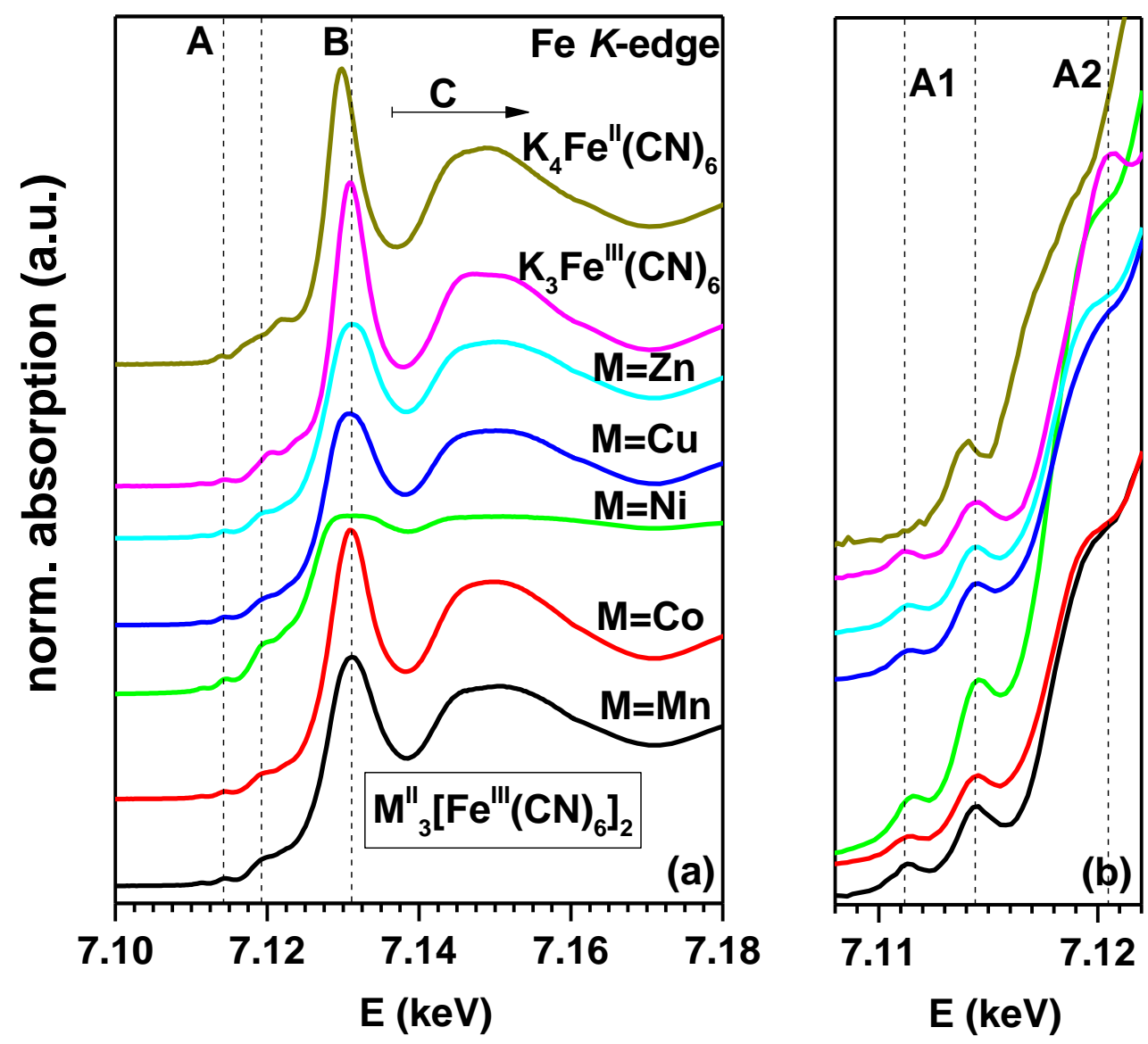

FIG. 4. (a) Fe K-edge XANES spectra for the compounds of the metal(II) hexacyanoferrates $(\mathrm{III})$ family $\mathrm{M}_{3}^{\mathrm{II}}\left[\mathrm{Fe}^{\mathrm{III}}(\mathrm{CN})_{6}\right]_{2},(\mathrm{~g})-(\mathrm{k})$, and the reference compounds $\mathrm{K}_{4}$ $\left[\mathrm{Fe}^{\prime \prime}(\mathrm{CN})_{6}\right]$ and $\mathrm{K}_{3}\left[\mathrm{Fe}^{\prime \prime \prime}(\mathrm{CN})_{6}\right]$. The energy scale is relative to the Fe $\mathrm{K}$-edge in iron metal (7.1120 keV). The dotted line between A and B shows the matching of the sample edge positions with the reference spectra of $\mathrm{K}_{3}\left[\mathrm{Fe}^{\prime \prime \prime}(\mathrm{CN})_{6}\right]$. The Fe $\mathrm{K}$-edge position for $\mathrm{K}$ ${ }_{4}\left[\mathrm{Fe}^{\|}(\mathrm{CN})_{6}\right]$ is shifted by $\sim 1 \mathrm{eV}$. (b) Detailed display of the pre-edge region $(A)$. 
Figure 4(b) illustrates the features in the pre-edge region (A) of the Fe $K$-edge XANES spectra of the metal hexacyanoferrates and the two reference compounds, $\mathrm{K}_{4}\left[\mathrm{Fe}^{\prime \prime}(\mathrm{CN})_{6}\right]$ and $\mathrm{K}_{3}\left[\mathrm{Fe}^{\prime \prime \prime}(\mathrm{CN})_{6}\right]$. In the reference compounds, both $\mathrm{Fe}(\mathrm{II})$ and $\mathrm{Fe}(\mathrm{III})$ atoms occupy centrosymmetric sites of octahedral coordination geometry and are coordinated with six carbon atoms. $\mathrm{K}_{4}\left[\mathrm{Fe}^{\prime \prime}(\mathrm{CN})_{6}\right]$ contains low-spin $\mathrm{Fe}(\mathrm{Is}, \mathrm{II})$ in a $\mathrm{d}^{6}$ electronic configuration, while the high-spin $\mathrm{Fe}(\mathrm{hs}, \mathrm{III})$ in $\mathrm{K}_{3}\left[\mathrm{Fe}^{\mathrm{III}}(\mathrm{CN})_{6}\right]$ is a d $\mathrm{d}^{5}$ system. The octahedral crystal field, present in these structures, causes splitting of the $3 d$ levels ( $3 d e_{g}$ and $3 d t_{2 g}$ ) of $\mathrm{Fe}(\mathrm{II})$ and $\mathrm{Fe}(\mathrm{III})$ atoms. Electronic transitions from the $1 \mathrm{~s}$ core level to these split levels are observed in the pre-edge regions of the XANES spectrum of the compounds. As seen in Figure4, there are two pre-edge peaks (A1) approximately at 7.1112 and $7.1144 \mathrm{keV}$ in $\mathrm{K}_{3}\left[\mathrm{Fe}^{\prime \prime \prime}(\mathrm{CN})_{6}\right]$ which correspond to the electronic transitions $1 s \rightarrow 3 d t_{2 g}$ and $1 s \rightarrow 3 d e_{g}$ respectively. ${ }^{16,17}$ For $\mathrm{K}_{4}\left[\mathrm{Fe}(\mathrm{CN})_{6}\right]$, one small peak at $\sim 7.1140 \mathrm{keV}$ is observed in the pre-edge region. This peak is attributed to the electronic transition $1 s \rightarrow 3 d e_{g}$. The $1 s \rightarrow 3 d t_{2 g}$ transition is not observed since the $3 d t_{2 g}$ level is completely occupied by the six electrons $\left(d^{6}\right)$ for low-spin Fe(II). ${ }^{16,17}$ The rising feature (A2) just below the edge position occurs because of the rising threshold of $1 s \rightarrow 4 p$ dipole-allowed transitions. ${ }^{18}$ This preedge feature is also present in all the sample spectra at the same energy as for $\mathrm{K}$ ${ }_{3}\left[\mathrm{Fe}(\mathrm{CN})_{6}\right]$ while this feature is shifted to lower energy for $\mathrm{K}_{4}\left[\mathrm{Fe}(\mathrm{CN})_{6}\right]$. This indicates that the iron atoms in the samples are in oxidation state (III).

The main edge (B) has been chosen at the first inflection point after the pre-edge region. The main edge position occurs at $7.1290 \mathrm{keV}$ for the model compound $\mathrm{K}$ ${ }_{3}\left[\mathrm{Fe}(\mathrm{CN})_{6}\right]$ as well as for all the hexacyanoferrates(III) samples. This confirms that the Fe atoms of the samples are in the (III) oxidation state. The edge position for $\mathrm{K}_{4}\left[\mathrm{Fe}(\mathrm{CN})_{6}\right]$ was found to be shifted to lower energy by $1 \mathrm{eV}$ and it occurs at $7.1280 \mathrm{keV}$. The first intense resonance peak (absorption maxima) occurs at $\sim 7.1309 \mathrm{keV}$ for $\mathrm{K}_{3}\left[\mathrm{Fe}(\mathrm{CN})_{6}\right]$ while the same peak occurs at $\sim 7.1298 \mathrm{keV}$ for $\mathrm{K}$ ${ }_{4}\left[\mathrm{Fe}(\mathrm{CN})_{6}\right]$. This $1 \mathrm{eV}$ difference in the $\mathrm{Fe} K$ edge position and of the absorption maxima is characteristic of the difference in oxidation state for iron between (III) to (II). ${ }^{16,17,19}$ This shift occurs because of multiple reasons such as the difference in the binding energies of the $1 s$ core initial state, difference in the Fe-C distances, and difference in the $\mathrm{C}-\mathrm{N}$ distances. ${ }^{9}$ The post edge region (C) of the sample spectra 
resemble each other and are very similar as the spectrum of $\mathrm{K}_{3}\left[\mathrm{Fe}(\mathrm{CN})_{6}\right]{ }^{17,19}$ The spectrum of $\mathrm{Ni}_{3}\left[\mathrm{Fe}(\mathrm{CN})_{6}\right]_{2}$ exhibits a low intensity of the absorption maxima and very broad peak shapes. This is occurring due to the thickness of the measured sample pellet being too large.

Very similar spectral features displayed by the hexacyanoferrate(III) compounds indicate a similar local structure around the $\mathrm{Fe}$ atom, which is essentially " $\mathrm{Fe}(\mathrm{CN})_{6}$," for all these samples. The clear matching of the absorption edge of the sample spectra with the $\mathrm{K}_{3}\left[\mathrm{Fe}(\mathrm{CN})_{6}\right]$ reference spectrum rules out the possibility of mixed oxidation states of $\mathrm{Fe}$ in these samples and confirm iron in the oxidation state (III).

\subsubsection{Metal Hexacyanoferrates(II)}

Figure 5 depicts the Fe $K$-edge XANES spectral features of five metal hexacyanoferrates(II) $\mathrm{M}_{2}\left[{ }_{2}\left[\mathrm{Fe}^{\prime \prime}(\mathrm{CN})_{6}\right]\right.$ (Table I, (o) - (s)), together with the reference compounds $\mathrm{K}_{4}\left[\mathrm{Fe}(\mathrm{CN})_{6}\right]$ and $\mathrm{K}_{3}\left[\mathrm{Fe}(\mathrm{CN})_{6}\right]$.
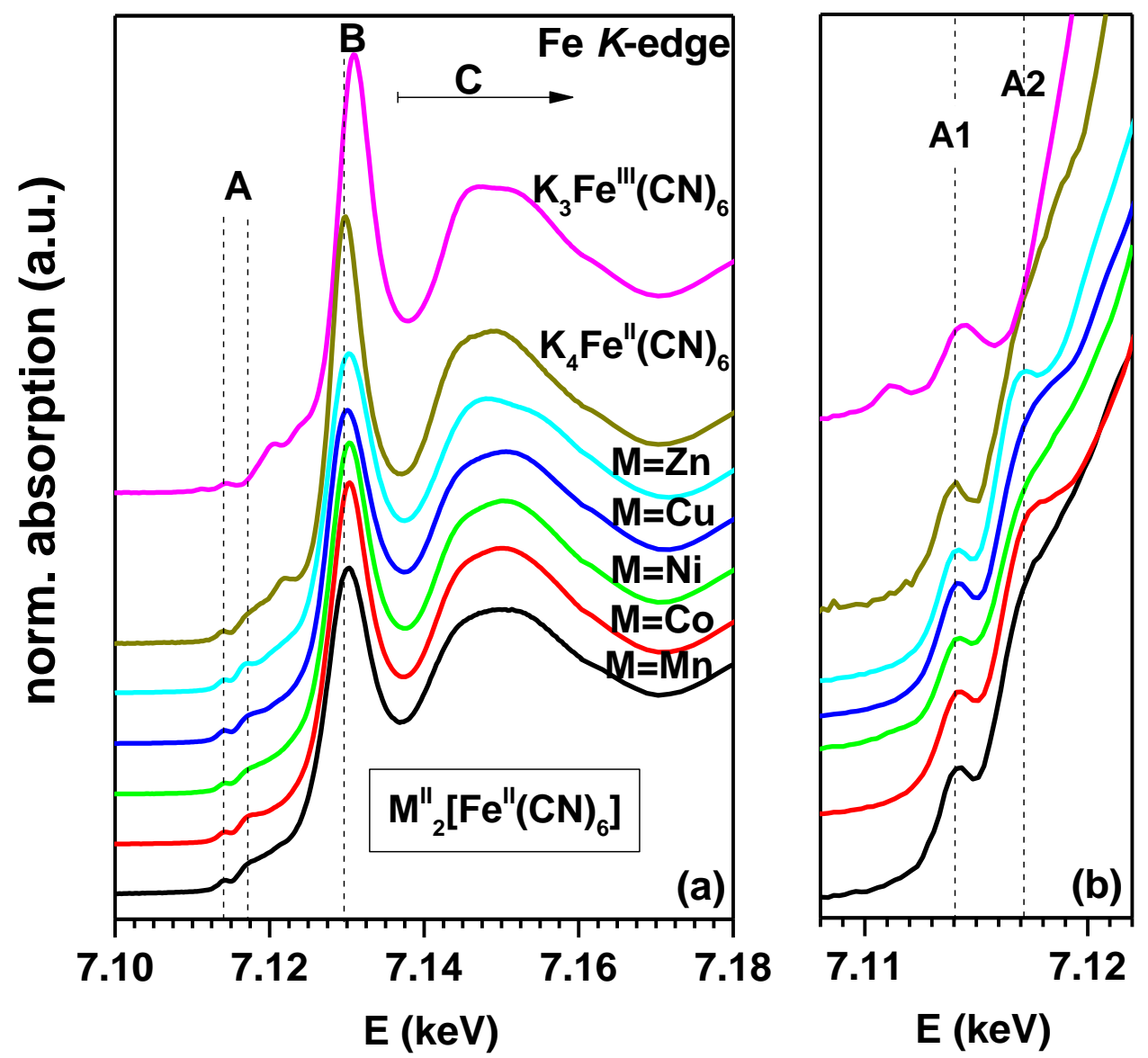

FIG. 5. (a) Fe K-edge XANES spectra of the compounds of the metal hexacyanoferrate(II) family $\mathrm{M}_{2}{ }_{2}\left[\mathrm{Fe}^{\prime \prime}(\mathrm{CN})_{6}\right],(\mathrm{o})-(\mathrm{s})$, and the reference compounds $\mathrm{K}_{4}\left[\mathrm{Fe}^{\prime \prime}(\mathrm{CN})_{6}\right]$ and $\mathrm{K}_{3}\left[\mathrm{Fe}^{\mathrm{III}}(\mathrm{CN})_{6}\right]$. 
The energy scale is relative to the Fe $K$-edge in iron metal $(7.112 \mathrm{keV})$. The dotted line $B$ indicates matching edge positions for all samples and the Fe" reference and a $\sim 1 \mathrm{eV}$ highenergy shift for the Fe ${ }^{\text {III }}$ reference. (b) The respective XANES pre-edge features.

As can be seen, all the sample spectra show similar features indicating essentially the same local structure "Fe $(\mathrm{CN})_{6}$ " around the target atom Fe. If we compare the sample spectra to the reference spectra as discussed in the previous section, we find that the spectral signatures for the samples seem to match closely with that of reference compound $\mathrm{K}_{4}\left[\mathrm{Fe}(\mathrm{CN})_{6}\right]$ suggesting the oxidation state of Fe atom in the compound to be (II).

The pre-edge region (A) of all the sample spectra (Fig. 5(b)) contains a small resonance peak (A1) attributed to the electronic transitions $1 s \rightarrow 3 d e_{g}(\mathrm{Fe}(\mathrm{Is}, \mathrm{II}))$ and a small rising feature (A2) for the $1 s \rightarrow 4 p$ dipole-allowed transition. While the rising feature is more prominent for the sample spectra than for the reference, it is still present in the spectrum of $\mathrm{K}_{4}\left[\mathrm{Fe}(\mathrm{CN})_{6}\right]$. The main edge positions $(\mathrm{B})$ for the samples have been identified from the first inflection point after the pre-edge region and match well with the main edge position of the reference $\mathrm{K}_{4}\left[\mathrm{Fe}(\mathrm{CN})_{6}\right]$ (as indicated by the dotted line).

This confirms that the Fe atoms in the hexacyanoferrate(II) samples are in (II) oxidation state. The post-edge region (C) of the sample spectra also show same signature as the post-edge region for $\mathrm{K}_{4}\left[\mathrm{Fe}(\mathrm{CN})_{6}\right]$ implying similar local environment for the Fe atom in the samples.

\subsubsection{Mixed Iron(II)/Cobalt(II) Hexacyanocobaltates (III)}

Figure 6 shows the Fe $K$-edge XANES spectra of the mixed iron(II)-cobalt(II) hexacyanocobaltates(III) $\left[\mathrm{Fe}_{(1-\mathrm{x})} \mathrm{Co}_{\mathrm{x}}{ }_{3}\right]_{3}\left[\mathrm{Co}^{\prime \prime \prime}(\mathrm{CN})_{6}\right]_{2}$ with $\mathrm{x}=0,0.25,0.5,0.75$ (Table I, (b),(t)-(v)). The reference compounds are $\mathrm{K}_{4}\left[\mathrm{Fe}(\mathrm{CN})_{6}\right]$ and $\mathrm{K}_{3}\left[\mathrm{Fe}(\mathrm{CN})_{6}\right]_{2}$. 

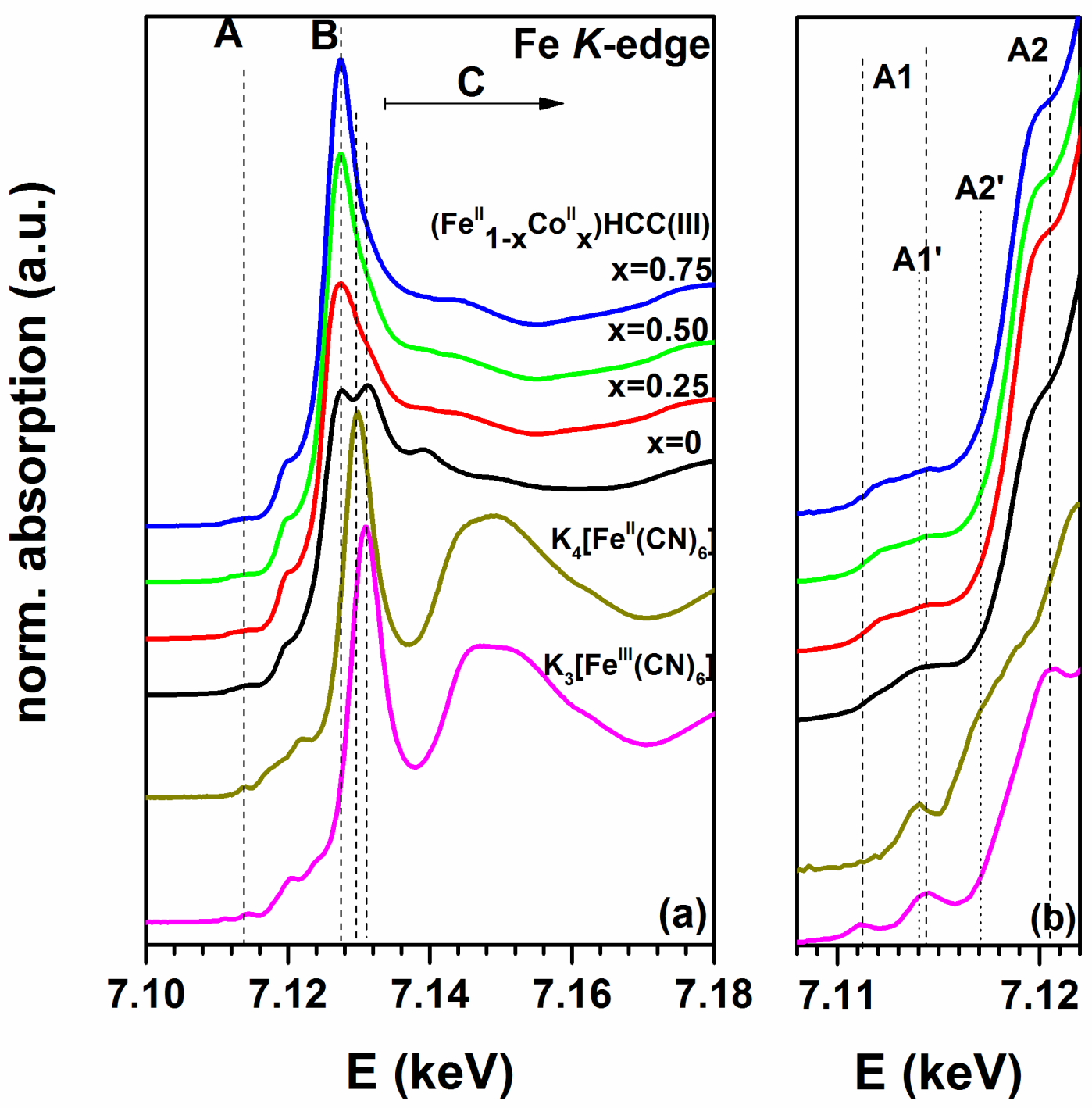

FIG. 6. (a) Fe K-edge XANES spectra for mixed iron(II)/cobalt(II) hexacyanocobaltates(III) (short: $\mathrm{HCC}(\mathrm{III}))\left[\mathrm{Fe}_{(1-x)}{ }_{(1-\mathrm{Co}}{ }_{\mathrm{x}}\right]_{3}\left[\mathrm{Co}^{\mathrm{III}}(\mathrm{CN})_{6}\right]_{2},(\mathrm{~b}),((\mathrm{t})-(\mathrm{v})$, together with the reference compounds $\mathrm{K}_{4}\left[\mathrm{Fe}(\mathrm{CN})_{6}\right]$ and $\mathrm{K}_{3}\left[\mathrm{Fe}(\mathrm{CN})_{6}\right]$. The energy scale is relative to the Fe $\mathrm{K}$-edge in metal $(7.112 \mathrm{keV})$. The dotted lines indicate the edge positions. (b) The respective XANES pre-edge features.

The hexacyanocobaltates(III) $\left[\mathrm{Fe}_{(1-x)}{ }^{\prime \prime} \mathrm{Co}_{\mathrm{x}}{ }_{\mathrm{x}}\right]_{3}\left[\mathrm{Co}^{\prime \prime \prime}(\mathrm{CN})_{6}\right]_{2}$ with mixed amounts of $\mathrm{Fe}(\mathrm{II})$ and $\mathrm{Co}$ (II) show a very sharp edge feature at $7.128 \mathrm{keV}$ (B - left dashed line) that is below the edge crest of the $\mathrm{Fe}(\mathrm{II})$ compound $\mathrm{K}_{4}\left[\mathrm{Fe}(\mathrm{CN})_{6}\right]$ at $7.130 \mathrm{keV}(\mathrm{B}$ middle dashed line). This shift to lower energies can be explained by the presence of high-spin $\mathrm{Fe}(\mathrm{II})$ ions $(\mathrm{Fe}(\mathrm{hs}, \mathrm{II}))$ in the hexacyanocobaltates(III) while $\mathrm{K}_{4}\left[\mathrm{Fe}(\mathrm{CN})_{6}\right]$ contains low-spin $\mathrm{Fe}(\mathrm{Is}, \mathrm{II}) .{ }^{38}$ The occurrence of these high-spin $\mathrm{Fe}(\mathrm{hs}, \mathrm{II})$ ions goes 
along with their bond to the "N"-end of the cyanide (CN) ligand instead of the " $\mathrm{C}$ "end: --Fe ${ }^{\text {hs, II }}-\mathrm{N} \equiv \mathrm{C}-\mathrm{Co}-\mathrm{C} \equiv \mathrm{N}-\mathrm{Fe}^{\text {hs, II }}$. In $\mathrm{K}_{4}\left[\mathrm{Fe}(\mathrm{CN})_{6}\right]$, low-spin $\mathrm{Fe}(\mathrm{Is}, \mathrm{II})$ is bound to the carbon of the cyanide ligand $-\mathrm{N} \equiv \mathrm{C}-\mathrm{Fe} \mathrm{e}^{\mathrm{Is}, \mathrm{II}}-\mathrm{C} \equiv \mathrm{N}$ - and showing the edge position at $7.130 \mathrm{keV} .{ }^{39}$ With increasing iron content in the hexacyanocobaltates(III), a shoulder of increasing intensity appears at energies higher than for $\mathrm{Fe}^{\mathrm{hs}, \mathrm{Il}}$ or $\mathrm{Fe} \mathrm{e}^{\mathrm{ls}, \mathrm{ll}}$ but rather at the region where the signal for $\mathrm{Fe}^{\mathrm{ls}, \mathrm{III}}$ appears in the $\mathrm{K}_{3}\left[\mathrm{Fe}(\mathrm{CN})_{6}\right]$ spectrum. This indicating partial oxidation of $\mathrm{Fe}(\mathrm{II})$ to $\mathrm{Fe}(\mathrm{III})$. Pure iron(II) hexaxyanocobaltate(III) $(\mathrm{X}=0)$ with the highest possible Fe concentration shows clearly two resonance peaks, $\mathrm{Fe}(\mathrm{Is}, \mathrm{II})$ and $\mathrm{Fe}(\mathrm{III})$, respectively.

Equivalent observations can be made in the pre-edge region. (A1) and (A2) are pre-edge features corresponding to $\mathrm{Fe}(\mathrm{hs}, \mathrm{II})$ in $\mathrm{K}_{4}\left[\mathrm{Fe}(\mathrm{CN})_{6}\right]$ while the first dashed line (no label), (A1') and (A2') belong to $\mathrm{Fe}(\mathrm{Is}, \mathrm{III})$ in $\mathrm{K}_{3}\left[\mathrm{Fe}(\mathrm{CN})_{6}\right]$. The pre-edge features (A1) and (A1') are fairly sharp for the respective reference compound, while these features are extremely broad for all hexacyanocobaltates(III) ranging from 7.1112 to $7.1145 \mathrm{keV}$ indicating a mixed oxidation state. While there is a quite distinctive feature at $7.1103 \mathrm{keV}\left(\mathrm{A} 2^{\prime}\right)$ for $\mathrm{K}_{4}\left[\mathrm{Fe}(\mathrm{CN})_{6}\right]$ which correspond to the $1 s-4 p$ transition for $\mathrm{Fe}(\mathrm{II})$, a similar but much narrower feature can be found for the hexacyanocobaltates(III).

During synthesis of these bimetallic compounds, iron(II) is partially oxidized to iron(III). This occurs visibly for iron contents larger than $25 \%(x=0.75)$. The oxidation states of cobalt in these compounds will be discussed in the CoKXANES section.

\subsubsection{Mixed Iron(II)/Cobalt(II) Hexacyanoferrates(III) and $\mathrm{Fe}_{3}\left[\mathrm{Cr}(\mathrm{CN})_{6}\right]_{2}$}

The results for the mixed hexacyanoferrates(III) $\left[\mathrm{Fe}_{(1-x)}{ }_{\left(1-\mathrm{Co}^{\prime \prime}\right.}\right]_{3}\left[\mathrm{Fe}^{\mathrm{III}}(\mathrm{CN})_{6}\right]_{2}$ with $\mathrm{x}=0.25,0.5,0.75$ and the iron(II) hexacyanochromate (Table I, (w)-(y),(I)) look quite different from the mixed hexacyanocobaltates(III) (Figure 7). The spectra are dominated by the signal of the $\mathrm{Fe}(\mathrm{III})$ species - a broad absorption edge at $7.1309 \mathrm{keV}$. The pre-edge region looks interesting since there is one absorption peak at $7.1140 \mathrm{keV}\left(\mathrm{A} 1^{\prime}\right)$ as observed for $\mathrm{Fe}$ (Is,II) ions as well as a broad peak around $7.1171 \mathrm{keV}\left(\mathrm{A}^{\prime}\right)$. These two peak areas increase for the hexacyanoferrates(III) with increasing $\mathrm{Fe}(\mathrm{II})$ amounts in the sample ( $\mathrm{x}=0.75$ to 0.25 ) indicating that the pre-edge is dominated by $\mathrm{Fe}(\mathrm{II})$. 


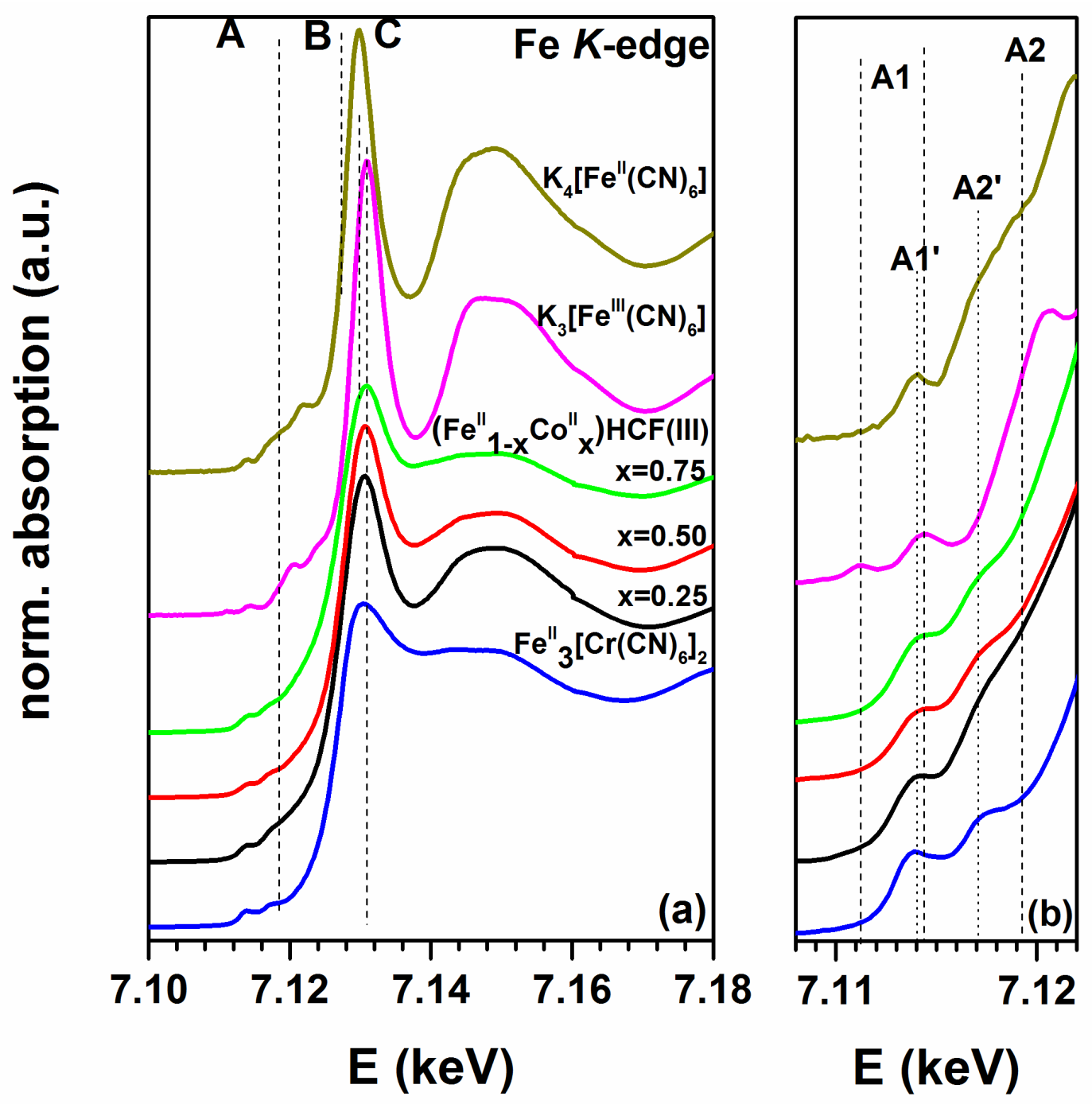

FIG. 7. Fe K-edge XANES spectra of $\mathrm{Fe}(\mathrm{II}) / \mathrm{Co}(\mathrm{II})$ hexacyanoferrates(III) [Fe" ${ }_{(1-}$ $\left.{ }_{x)} \mathrm{Co}_{\mathrm{x}}{ }_{\mathrm{x}}\right]_{3}\left[\mathrm{Fe}^{\mathrm{III}}(\mathrm{CN})_{6}\right]_{2}$ (short: $\left.\mathrm{HCF}(\mathrm{III})\right)$ together with the reference compounds $\mathrm{K}_{4}\left[\mathrm{Fe}(\mathrm{CN})_{6}\right]$, K${ }_{3}\left[\mathrm{Fe}(\mathrm{CN})_{6}\right]$, and $\mathrm{Fe}(\mathrm{II})$ hexacyanochromate $(\mathrm{III})\left(\mathrm{Fe}_{3}\left[\mathrm{Cr}(\mathrm{CN})_{6}\right]_{2}\right)$. The energy scale is relative to the Fe $K$-edge in iron metal $(7.112 \mathrm{keV})$. The dotted lines indicate the edge positions. (b) The respective XANES pre-edge features.

The higher-energy (A1) signal as observed for $\mathrm{K}_{3}\left[\mathrm{Fe}(\mathrm{CN})_{6}\right]$ might still be present underneath the (A1') peak of the hexacyanoferrates(III), however the lower energy (A1) peak is missing. This can be due a reduction of the $1 s \rightarrow 3 d t_{2 g}$ transition intensity for low-spin $\mathrm{Fe}$ (Is,III). Low-spin $\mathrm{d}^{5}$ systems have two full and one halfoccupied $t_{2 g}$ orbital, leaving only one transition possibility, whereas high-spin $\mathrm{d}^{5}$ systems as present in $\mathrm{K}_{3}\left[\mathrm{Fe}^{\prime \prime \prime}(\mathrm{CN})_{6}\right]$ have three half occupied $\mathrm{t}_{2 \mathrm{~g}}$ orbitals open allowing for the transition into three orbitals. The edges $\mathrm{B}$ of the 
hexacyanoferrates(III) shift very slightly with increasing $\mathrm{Fe}(\mathrm{II})$ content ( $\mathrm{X}=0.75$ to $X=0.25$ ) towards lower energies as expected but line up well with edge of $\mathrm{K}_{3}\left[\mathrm{Fe}(\mathrm{CN})_{6}\right]$ clearly indicating a majority of $\mathrm{Fe}(\mathrm{III})$ in all samples.

The area after the absorption edge $(\mathrm{C})$ is comparable for all hexacyanoferrate(III) samples. Again with increasing Fe(II) amounts the shape becomes more distinctive indicating a better ordered lattice. As expected from the synthesis, a mixture of Fe(II) and $\mathrm{Fe}(\mathrm{III})$ is present in the hexacyanoferrates(III) with $\mathrm{x}=0.25-0.75$.

The spectrum of the iron in iron(II) hexacyanochromate(III) has a lot in common with the hexacyanoferrates(III). The pre-edge features (A1') and (A2') can be found in the spectrum of $\mathrm{Fe}_{3}\left[\mathrm{Cr}(\mathrm{CN})_{6}\right]_{2}$ agreeing with the $1 s \rightarrow 3 d$ and the $1 s \rightarrow 4 p$ transition as found in $\mathrm{K}_{4}\left[\mathrm{Fe}(\mathrm{CN})_{6}\right]$. Fe(III) cannot be excluded from the features in the pre-edge region. The edge itself is situated between $\mathrm{Fe}(\mathrm{II})$ and $\mathrm{Fe}(\mathrm{III})$ implying a mixed oxidation state of iron.

\subsection{Co $K$-edge XANES}

\subsubsection{Metal(II) Hexacyanocobaltates(III)}

Figure 8 shows the normalized Co K-edge XANES spectra of metal(II) hexacyanocobaltates(III) $\mathrm{M}_{3}{ }_{3}\left[\mathrm{Co}(\mathrm{CN})_{6}\right]_{2}$ (Table I, (a),(b),(d)-(f)) containing features in the pre-edge $(A)$, main edge $(B)$ and post-edge $(C)$ regions along with the reference compounds $\mathrm{Co}, \mathrm{Co}^{\prime \prime} \mathrm{O}$ and $\mathrm{K}_{3}\left[\mathrm{Co}^{\prime \prime \prime}(\mathrm{CN})_{6}\right]$. All sample spectra resembles the spectra of the $\mathrm{K}_{3}\left[\mathrm{Co}^{\mathrm{III}}(\mathrm{CN})_{6}\right]$ reference indicating the presence of $\mathrm{Co}(\mathrm{III})$ in the samples.

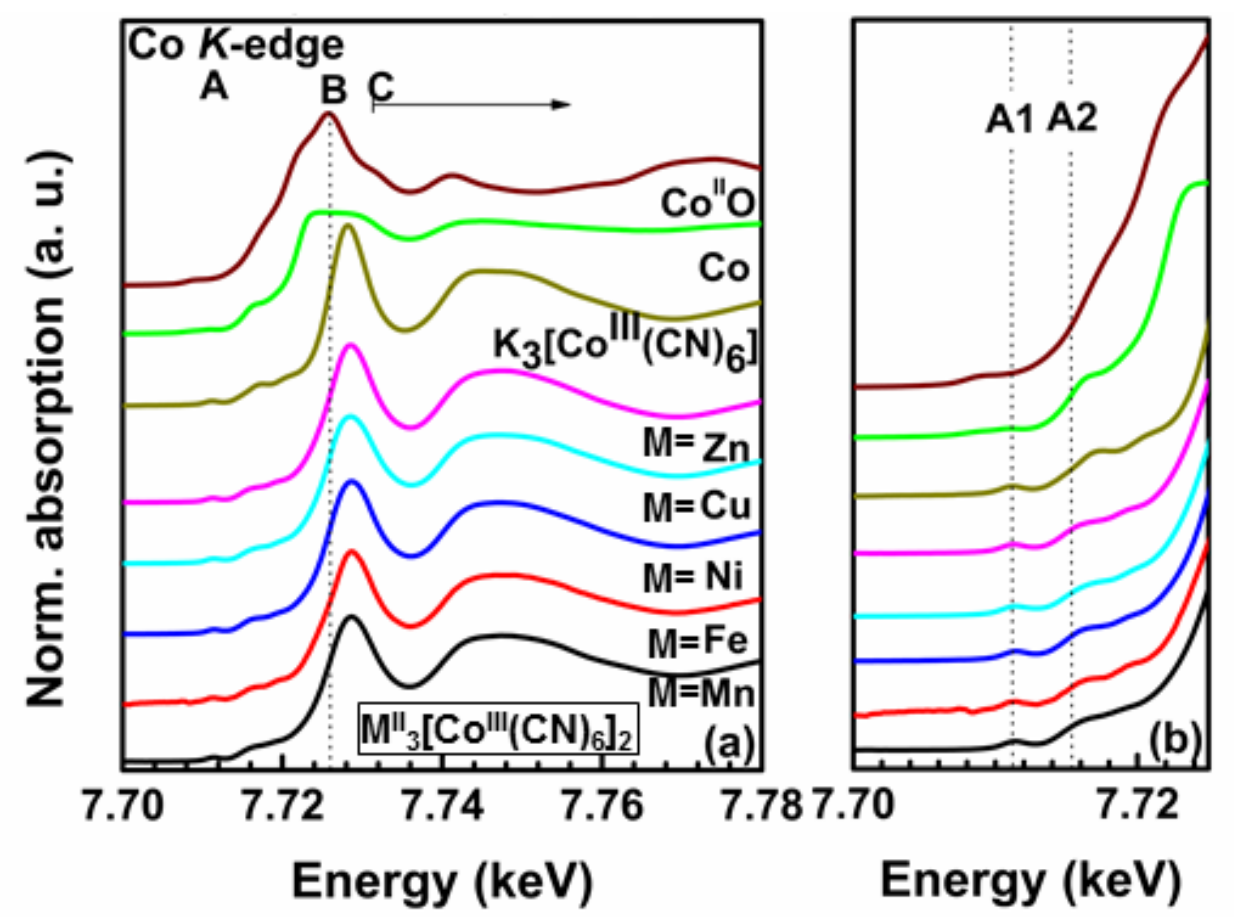


FIG. 8. (a) Co K-edge XANES spectra of the metal(II) hexacyanocobaltates(III) $\mathrm{M}_{3}\left[\mathrm{Co}(\mathrm{CN})_{6}\right]_{2}$ $(\mathrm{M}=\mathrm{Zn}, \mathrm{Cu}, \mathrm{Ni}, \mathrm{Fe}, \mathrm{Mn})$ together with the reference compounds $\mathrm{K}_{3}\left[\mathrm{Co}^{\prime \prime \prime}(\mathrm{CN})_{6}\right]$, $\mathrm{Co}^{\prime \prime} \mathrm{O}$ and $\mathrm{Co}^{0}$. The energy scale is relative to the Co K-edge in metal $(7.709 \mathrm{keV})$. The dotted lines indicate the edge positions. (b) The details of the pre-edge regions for the respective XANES spectra.

In the reference compound $\mathrm{K}_{3}\left[\mathrm{Co}^{\prime \prime \prime}(\mathrm{CN})_{6}\right]$, a cobalt atom is coordinated with six carbon atoms of cyanide ligands, sharing an octahedral coordination geometry. Hence, the $3 d$ level of the cobalt atom splits into $3 d t_{2 g}$ and $3 d e_{g}$ levels because of the octahedral crystal field from $\mathrm{CoC}_{6}$ coordination. The pre-edge region (A) (see Fig. $8(b))$ of the XANES spectra of this reference compound contains a small resonance peak (A1) at $7.7111 \mathrm{keV}$ and a well resolved rising feature (A2) at $7.7160 \mathrm{keV}$ in the beginning of the absorption ramp. The small pre-edge resonance peak is attributed to the formally forbidden electronic transitions $1 s \rightarrow 3 d\left(t_{2 g}, e_{g}\right)$ which becomes partially allowed in a non-perfect centrosymmetric complexes. ${ }^{19-21}$ The rising feature just before the absorption band has also been observed by other researchers and has been assigned to allowed $1 s\left(\mathrm{a}_{1 g}\right) \rightarrow 3 d-\pi^{*}(\mathrm{CN})\left(\mathrm{t}_{1 u}\right)$ transitions. ${ }^{19,22}$ These preedge features are also clearly observed for all the sample spectra. The cobalt atom in the model compound $\mathrm{Co}$ "O, which has a $\mathrm{NaCl}$ type of structure, is coordinated with six oxygen atoms. A single pre-edge peak $(A 1)$ in the XANES spectra is observed at $7.7098 \mathrm{keV}$ which can be assigned to $1 \mathrm{~s} \rightarrow 3 d\left(\mathrm{t}_{2 \mathrm{~g}}, \mathrm{e}_{\mathrm{g}}\right)$ electronic transitions.

The main edge $(B)$ positions which have been determined from the inflection point after the pre-edge region occur at 7.7231 and $7.7261 \mathrm{keV}$ for $\mathrm{Co}$ (II) and Co(III) model compounds, respectively. The main edge positions for all hexacyanocobaltates(III) are the same as the one for Co(III) model compound implying presence of trivalent (as expected from synthesis) Co atoms in all the samples. The absorption maximum is observed to occur at $7.7255 \mathrm{keV}$ for Co"O while the same occurs at $7.7283 \mathrm{keV}$ for $\mathrm{K}_{3}\left[\mathrm{Co}^{\prime \prime \prime}(\mathrm{CN})_{6}\right]$. The absorption maxima for all the samples are observed to occur at the same position as the Co(III) in K${ }_{3}\left[\mathrm{Co}^{\prime \prime \prime}(\mathrm{CN})_{6}\right]$. The post-edge regions $(\mathrm{C})$ of all the sample spectra resemble each other and match with that of $\mathrm{K}_{3}\left[\mathrm{Co}^{\prime \prime \prime}(\mathrm{CN})_{6}\right]$. 
Since the spectral features of all the samples are similar to that of reference compound $\mathrm{K}_{3}\left[\mathrm{Co}^{\prime \prime \prime}(\mathrm{CN})_{6}\right]$, we conclude that the oxidation state of $\mathrm{Co}$ in all hexcayanocobaltates(III) is indeed (III).

\subsubsection{Mixed Iron(II)/Cobalt(II) Hexacyanocobaltates(III)}

Figure 9 depicts the normalized Co $K$-edge XANES spectra for the samples of the $\left(\mathrm{Fe}_{1-x} \mathrm{Co}_{\mathrm{x}}\right)_{3}\left[\mathrm{Co}(\mathrm{CN})_{6}\right]_{2}$ family $(\mathrm{x}=1.0,0.75,0.5,0.25,0.0)$ (Table I, (b)-(c), (t)-(v)) together with two reference spectra $\mathrm{Co}^{\prime \prime} \mathrm{O}$ and $\mathrm{K}_{3}\left[\mathrm{Co}^{\prime \prime \prime}(\mathrm{CN})_{6}\right]$. Figure 9 shows clearly that no spectrum uniquely matches closely with one of the reference spectra alone. There are two intense resonance peaks with varying strength which match with each reference compound resonance peaks. This indicates the presence of both $\mathrm{Co}$ (II) and $\mathrm{Co}(\mathrm{III})$ in all samples which is expected from synthesis. 

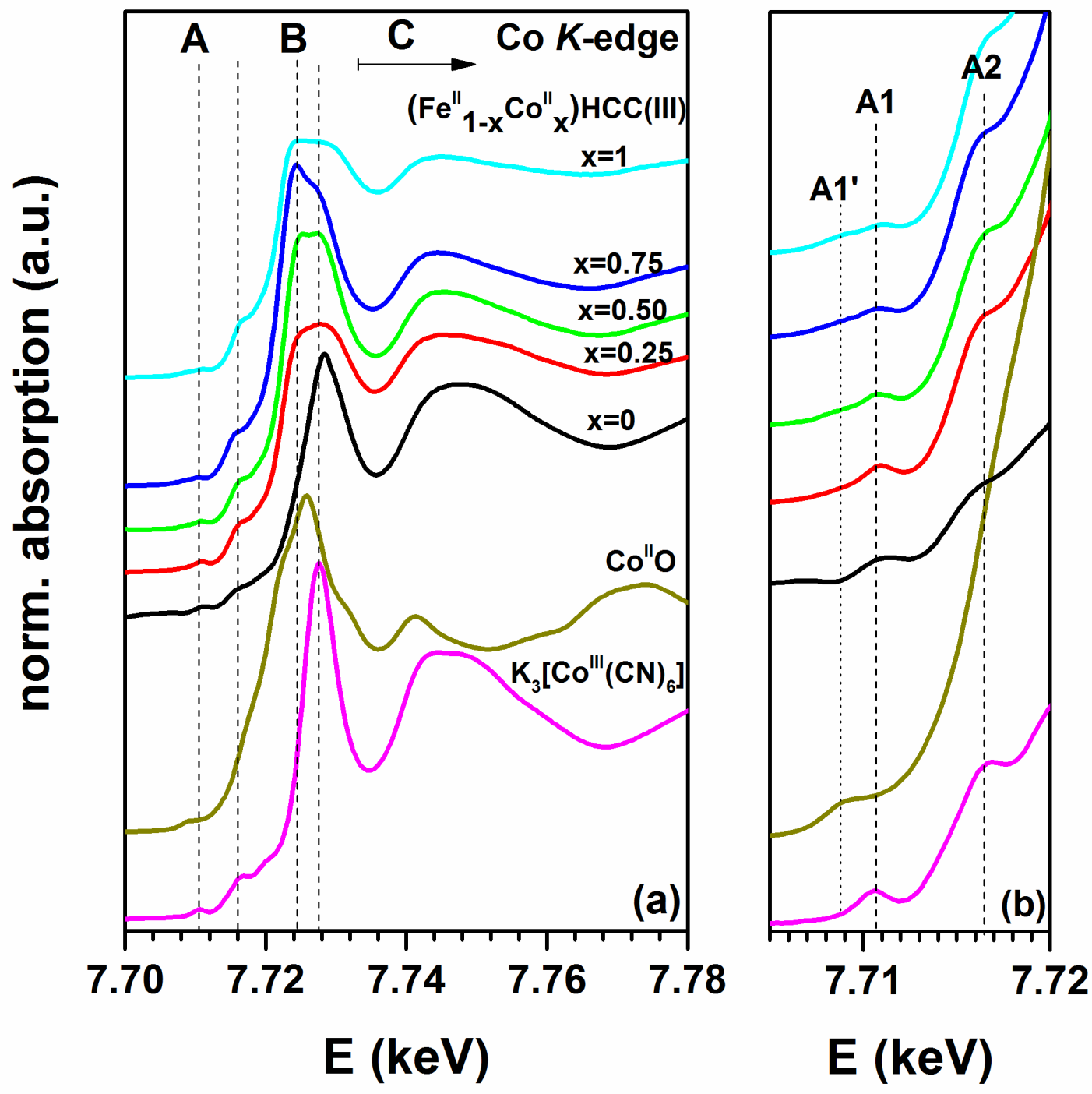

FIG. 9 (a) Co K-edge XANES spectra of the compounds of $\mathrm{Fe}(\mathrm{II}) / \mathrm{Co}(\mathrm{II})$

hexacyanocobaltates(III) (short: $\mathrm{HCC}(\mathrm{III}))\left(\mathrm{Fe}_{1-\mathrm{x}} \mathrm{Co}_{x}\right)_{3}\left[\mathrm{Co}(\mathrm{CN})_{6}\right]_{2}$ with $\mathrm{x}=0.0,25,0.5,0.75 .1$. Co K-edge XANES spectra of the reference compounds $\mathrm{K}_{3}\left[\mathrm{Co}^{\prime \prime \prime}(\mathrm{CN})_{6}\right]$ and $\mathrm{Co}^{\prime \prime} \mathrm{O}$ are also depicted. The energy scale is relative to the Co K-edge in metal $(7.709 \mathrm{keV})$. The dotted lines are guides through the edge positions. (b) The pre-edge region of the respective XANES spectra.

The pre-edge region (A) is shown in Fig. 9(b). As can be seen, the weak pre-edge peak $(\mathrm{A} 1)$, the $1 s \rightarrow 3 d$ transition for $\mathrm{Co}(\mathrm{III})$ in $\mathrm{K}_{3}\left[\mathrm{Co}^{\mathrm{III}}(\mathrm{CN})_{6}\right]$ occurs at around $7.1122 \mathrm{keV}$. This feature is observable in all hexacyanocobaltates(III). The rising feature (A2), discussed in previous section, occurs at $7.716 \mathrm{keV}$ for the Co(III) reference spectrum and is also present in all sample spectra. The features on the edge (B) of the hexacyanocobaltates(III) show the occurrence of two maxima. For 
$\left(\mathrm{Fe}_{1-\mathrm{x}} \mathrm{Co}_{\mathrm{x}}\right)_{3}\left[\mathrm{Co}(\mathrm{CN})_{6}\right]_{2}$, with $\mathrm{x}=0.75-0.25$, two maxima at $\sim 7.7260$ and $\sim 7.7281 \mathrm{keV}$ (dotted lines in Fig. 9(a)) match the absorption maxima of $\mathrm{Co}$ (II) in $\mathrm{CoO}$ and $\mathrm{Co}(\mathrm{Is}, \mathrm{III})$ of the other reference spectrum. While the intensity of the Co(III) maximum stays the same in all three samples containing the hexacyanocobaltate ion, $\left[\mathrm{Co}^{\prime \prime \prime}(\mathrm{CN})_{6}\right]^{3-}$, the intensity of the $\mathrm{Co}(\mathrm{II})$ peak decreases with decreasing cobalt content as expected. For $\mathrm{x}=0, \mathrm{Fe}_{3}\left[\mathrm{Co}(\mathrm{CN})_{6}\right]_{2}$, the spectrum shows only $\mathrm{Co}(\mathrm{III})$, while for $\mathrm{x}=1, \mathrm{Co}_{3}\left[\mathrm{Co}(\mathrm{CN})_{6}\right]_{2}$, a very broad maximum spans the whole area.

A closer look (see inset of fig. 9 (b)) at the pre-edge features indicates that the intensity of (A1) (feature for Co $\mathrm{C}^{\mathrm{III}}$ ) increases while the intensity of (A1') (feature for Co") decreases with decreasing cobalt content.

The post edge $\mathrm{C}$ regions for the three samples are similar to each other. The features look sharper with decreasing cobalt content indicating better order around the Co atoms with decreasing Co content.

\subsubsection{Mixed Iron(II)/Cobalt(II) Hexacyanoferrates(III)}

Figure 10 shows the normalized XANES spectra for the $\left(\mathrm{Fe}_{1-\mathrm{x}} \mathrm{Co}_{\mathrm{x}}\right)_{3}\left[\mathrm{Fe}(\mathrm{CN})_{6}\right]_{2}$ family (Table I, (h),(w)-(y)) together with the two reference spectra. The main XANES spectra containing all three regions (A, B, and $C)$ are shown in Fig. 10(a) and the pre-edge features are shown more clearly in Fig. 10(b). As can be seen, like the previous family of compounds, no sample spectra match uniquely with either of the reference spectra but carries signatures from both the model spectra. This indicates the presence of both $\mathrm{Co}(\mathrm{II})$ and $\mathrm{Co}(\mathrm{III})$ in the samples. 

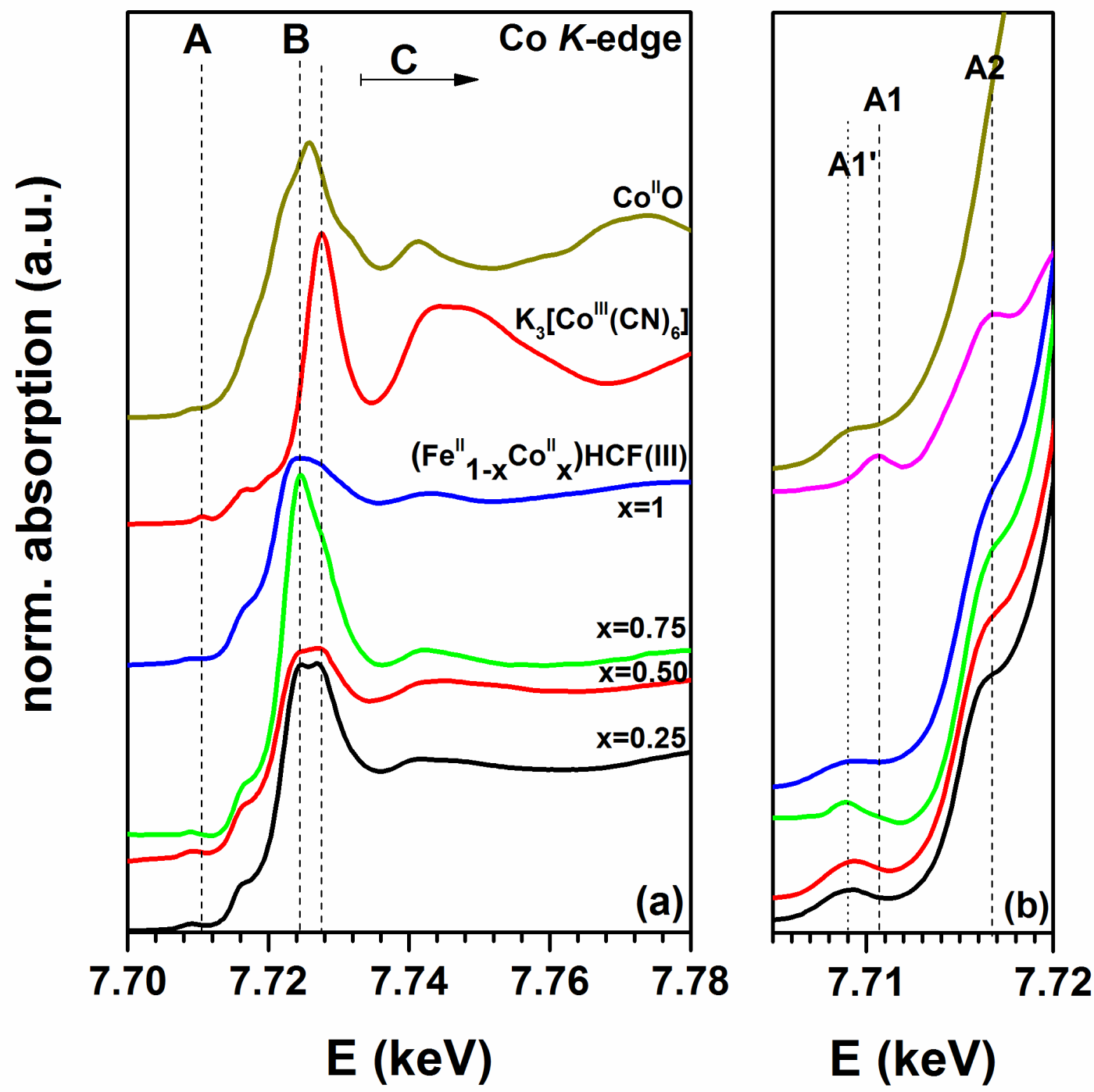

FIG. 10. (a) Co K-edge XANES spectra of the mixed Fe(II)/Co(II) hexacyanoferrates(III) (short: $\mathrm{HCF}(\mathrm{III}))\left(\mathrm{Fe}_{1-\mathrm{x}} \mathrm{Co}_{\mathrm{x}}\right)_{3}\left[\mathrm{Fe}(\mathrm{CN})_{6}\right]_{2}$ and reference compounds $\mathrm{K}_{3}\left[\mathrm{Co}(\mathrm{CN})_{6}\right]_{2}$ and $\mathrm{CoO}$. The left panel(a) shows the full XANES spectra and the right panel (b) shows a detailed few of the pre-edge. The energy scale is relative to the Co $K$-edge in metal $(7.709 \mathrm{keV})$. The dotted lines indicate the edge positions.

The pre-edge region (A) contains a weak peak (A1) ( $1 s \rightarrow 3 d$ transition) and a rising feature (possibly from $1 s\left(\mathrm{a}_{1 g}\right) \rightarrow 3 d-\pi^{*}(\mathrm{CN})\left(\mathrm{t}_{1 u}\right)$ transitions). The position of peak (A1) for the hexacyanoferrate(III) with $\mathrm{x}=0.25$ is close to the position of (A1) in the $\mathrm{Co}(\mathrm{III})$ reference $\mathrm{K}_{3}\left[\mathrm{Co}(\mathrm{CN})_{6}\right]_{2}$. As $\mathrm{x}$ increases from $\mathrm{x}=0.25$ to 0.5 and 0.75 , respectively, peak (A1) moves closer to the (A1') position of the $\mathrm{Co}^{\prime \prime}$ model spectrum $\mathrm{CoO}$. The occurrence of these features is indicative of the distorted octahedral surrounding of the absorbing Co atom. 
The main edge (B) has been determined again from the first inflection point after the pre-edge region and, for the samples, it occurs at $\sim 7.7227 \mathrm{keV}$ which is very close to the edge of the $\mathrm{Co}$ (II) model compound. Hence, most of the Co atoms in the sample are in oxidation state (II). However, all three sample spectra show the presence of two absorption maxima (see Figure 10(a)) which matches closely with the position of the absorption maxima for $\mathrm{Co}$ (II) and $\mathrm{Co}$ (III) model spectra. This indicates, qualitatively, that some percentage of the Co atoms may actually be in oxidation state (III) agreeing with the observations for the pre-edge region (shift of A1 towards A $\left.1^{\prime}\right)$. The post-edge region of the sample spectra looks flat and a hint of a very broad peak is observed.

\subsubsection{Cobalt(II/III) Hexacyanometallates(II/III)}

The Co $K$-edge XANES spectra for a selection of cobalt hexacyanometallates $\mathrm{Co}_{3}\left[\mathrm{Fe}(\mathrm{CN})_{6}\right]_{2}, \mathrm{Co}_{3}\left[\mathrm{Cr}(\mathrm{CN})_{6}\right]_{2}$ and $\mathrm{Co}_{2}\left[\mathrm{Fe}(\mathrm{CN})_{6}\right](\mathrm{Table} \mathrm{I},(\mathrm{h}),(\mathrm{m}),(\mathrm{p}))$ - are shown in Figure 11 together with the two reference spectra.

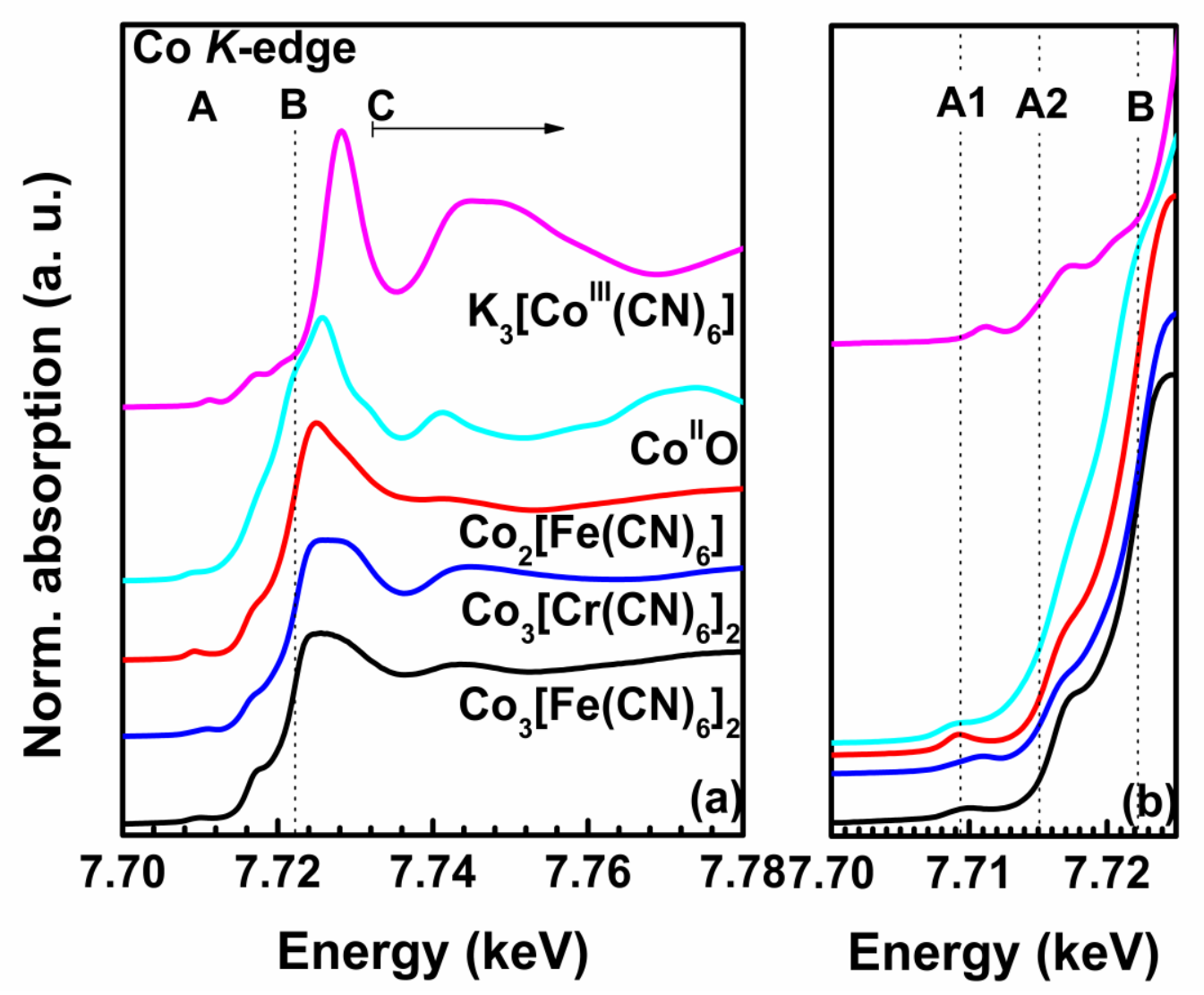


FIG. 11. (a) Co K-edge XANES spectra of the compounds the compounds $\mathrm{Co}_{3}{ }_{3}\left[\mathrm{Fe}{ }^{\text {III }}(\mathrm{CN})_{6}\right]_{2}$ and $\mathrm{Co}_{3}{ }_{3}\left[\mathrm{Cr}^{\prime \prime \prime}(\mathrm{CN})_{6}\right]_{2}$ and $\mathrm{Co}_{2}{ }_{2}\left[\mathrm{Fe}^{\prime \prime}(\mathrm{CN})_{6}\right]$ together with the reference compounds $\mathrm{K}$ ${ }_{3}\left[\mathrm{Co}(\mathrm{CN})_{6}\right]$ and $\mathrm{CoO}$. The energy scale is relative to the Co $\mathrm{K}$-edge in metal $(7.709 \mathrm{keV})$. The dotted lines indicate the edge positions. (b) The details of the pre-edge regions for the respective XANES spectra.

The pre-edge regions (A) (see Fig. 11(b)) of the samples contain a small resonance peak (A1) and a rising feature (A2) owing to the electronic transition as discussed earlier. This implies that the Co atoms in the samples are in distorted octahedral surroundings. The week pre-edge peak $(\mathrm{A} 1)$ for the $\mathrm{Co}_{2}\left[\mathrm{Fe}(\mathrm{CN})_{6}\right]$ occurs at the same position ( 7.7091 keV) as the Co(II) reference compound. The (A1) peak for the other two compounds occurs at higher energies ( 7.7100 keV).

The main edges $(B)$ for the samples occur at $7.7225 \mathrm{keV}$ which is very close to the edge position of the Co(II) model spectra. The absorption maximum for the $\mathrm{Co}_{2}\left[\mathrm{Fe}(\mathrm{CN})_{6}\right]$ sample occurs approximately at the same position as the $\mathrm{Co}(\mathrm{II})$ model compound. The spectrum of $\mathrm{Co}_{2}\left[\mathrm{Fe}(\mathrm{CN})_{6}\right]$ seems to be different from the other two samples: The pre-edge features, edge position and the position and shape of the absorption maximum match more closely with the spectrum of model compound $\mathrm{Co}$ "O indicating the presence of divalent cobalt in the sample. However, for the other two samples there are signatures of double absorption maxima indicating both $\mathrm{Co}(\mathrm{II})$ and Co(III) may be present in these two samples.

The post-edge region $(\mathrm{C})$ of $\mathrm{Co}_{2}\left[\mathrm{Fe}(\mathrm{CN})_{6}\right]$ sample contains a broad peak at position close to the peak for Co" model spectra. In general, the spectral features seem to be the resultant of the combination of the two reference spectra. Therefore, it can be concluded that both $\mathrm{Co}^{\prime \prime}$ and $\mathrm{Co}^{\prime \prime \prime}$ are present in the PBAs $\mathrm{Co}_{3}\left[\mathrm{Cr}(\mathrm{CN})_{6}\right]_{2}$ and $\mathrm{CO}_{3}\left[\mathrm{Fe}(\mathrm{CN})_{6}\right]_{2}$.

\subsection{Ni $K$-edge XANES}

In Figure 12, the Ni K-edge XANES spectra of the PB analogs $\mathrm{Ni}_{3}\left[\mathrm{Co}(\mathrm{CN})_{6}\right]_{2}$, $\mathrm{Ni}_{3}\left[\mathrm{Fe}(\mathrm{CN})_{6}\right]_{2}, \mathrm{Ni}_{2}\left[\mathrm{Fe}(\mathrm{CN})_{6}\right], \mathrm{Ni}_{3}\left[\mathrm{Cr}(\mathrm{CN})_{6}\right]_{2}$ (Table I, (i),(q),(n)) together with reference spectra for $\mathrm{NiO}$ are shown. 


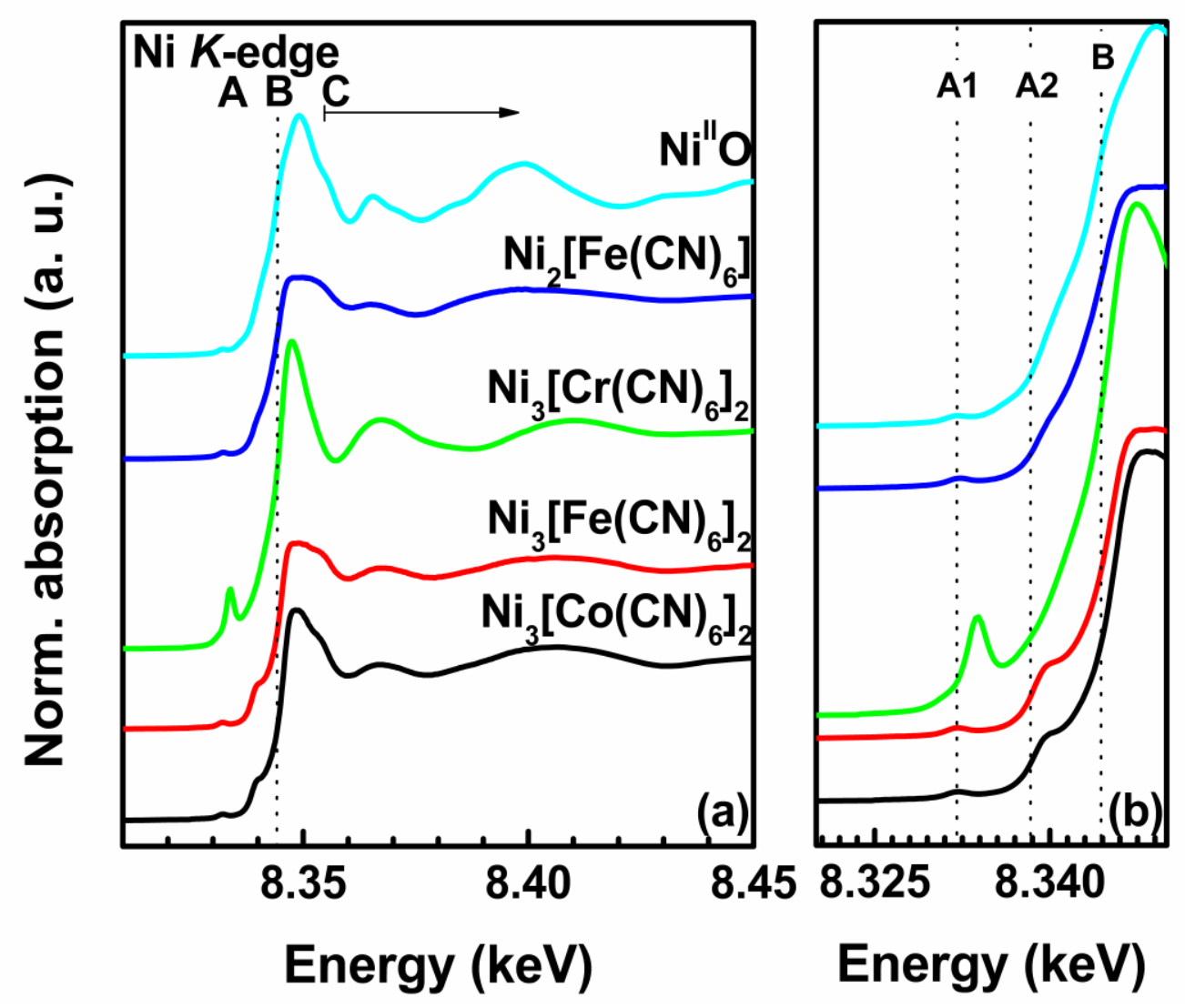

FIG. 12. (a) Ni K-edge XANES for the Prussian Blue analogs containing Ni, samples (d), (i), (n) and (q), along with that of the reference compound $\mathrm{Ni}^{\mathrm{ll}} \mathrm{O}$. The energy scale is relative to the Ni K-edge in metal $(8.333 \mathrm{keV})$. The dotted line indicates the edge positions. (b) The details of the pre-edge regions of the corresponding XANES spectra.

$\mathrm{NiO}$ crystallizes in the rock-salt $(\mathrm{NaCl})$ structure with each $\mathrm{Ni}$ atom surrounded by six octahedrally (point group $O_{h}$ ) coordinated oxygen atoms. The pre-edge region (A) of the spectra of $\mathrm{NiO}$ shows a small resonance peak (A1) at $\sim 8.332 \mathrm{keV}$, which is attributed to the $1 s \rightarrow 3 d$ electronic transition. The transition is forbidden in centrosymmetric point group. However, it appears because $\mathrm{Ni}$ atom in $\mathrm{NiO}$ structure does not sit in a centrosymmetric site and thus the octahedral coordination geometry around the $\mathrm{Ni}$ atom is distorted. The peak intensity increases as the symmetry around the Ni center becomes more distorted. This feature is also observed for all the samples indicating similar octahedral coordination geometry. In the samples, $\mathrm{Ni}$ atoms are octahedrally coordinated with $\mathrm{N}$ atoms. Some of the $\mathrm{N}$ atom sites may be partially occupied by $\mathrm{O}$ atoms from the disordered water present in the structures. 
The intensity of the small resonance peak is greater for the samples than the reference $\mathrm{NiO}$. This implies that the octahedral coordination geometry around the $\mathrm{Ni}$ atom is more distorted for the samples. Compared to the other spectra, the feature appears sharper and more intense in the spectrum of $\mathrm{Ni}_{3}\left[\mathrm{Cr}(\mathrm{CN})_{6}\right]_{2}$ compound indicating more distortion in the octahedral surrounding of the $\mathrm{Ni}$ atom for this sample. The pre-edge feature occurring due to $1 s \rightarrow 3 d$ transition, has also been observed in XANES spectra for the compounds with $\mathrm{Ni}$ in (II) oxidation state in earlier studies. ${ }^{23-26} \mathrm{~A}$ small shoulder like feature (A2) at $8.338 \mathrm{keV}$ is also observed just before the edge. The feature is prominent in the spectra for $\mathrm{Ni}_{3}\left[\mathrm{Co}(\mathrm{CN})_{6}\right]_{2}$, $\mathrm{Ni}_{3}\left[\mathrm{Fe}(\mathrm{CN})_{6}\right]_{2}$, visible faintly in the spectra of $\mathrm{Ni}_{2}\left[\mathrm{Fe}(\mathrm{CN})_{6}\right]$ and $\mathrm{NiO}$, and might be present in the $\mathrm{Ni}_{3}\left[\mathrm{Cr}(\mathrm{CN})_{6}\right]_{2}$ sample but broadened because of the sample thickness. This feature has also been observed in Nickel compounds by other researchers and has been assigned to $1 s \rightarrow 4 p_{z}$ transition. ${ }^{23,25,27}$ This transition usually appears as an intense peak for five coordinated $\mathrm{Ni}^{+2}$ complexes, for four coordinated geometry, and for square pyramidal Ni centers. The hint of the shoulder thus indicates the deviation from the complete six coordinated ocatahedral geometry and presence of significant amount of disorder.

The inflection point after the pre-edge shoulder (A2) is chosen as the main absorption edge (B). The main edge appears at $8.3441 \mathrm{keV}$ for $\mathrm{NiO}$ as well as for the samples implying (II) oxidation states for all the samples. The post-edge regions (C) for all the samples are very similar and show some resemblance with that of the NiO.

As illustrated, the sample spectra match closely with the spectra of $\mathrm{NiO}$ which indicates the presence of divalent $\mathrm{Ni}$ in the sample. However, the small resonance hump in the pre-edge region is sharper in the spectra of the $\mathrm{Ni}_{3}\left[\mathrm{Cr}(\mathrm{CN})_{6}\right]_{2}$ compound compared to other spectra. Moreover, the shoulder just before the edge is also less visible for this compound. It should be noted that significant amount of lattice water is present in the structures of these materials and the octahedral around the $\mathrm{Ni}$ atoms may not be complete since oxygen from the lattice water may be present in the octahedral. The amount of disordered water present in the octahedral coordination of the $\mathrm{Ni}$ atom varies in these structures. Hence, the possible distortion of the octahedral geometry also varies, which can account for any small differences observed in the spectra of the compounds. 


\subsection{Cu K-edge XANES}

Figure 13 shows the $\mathrm{Cu} K$-edge XANES spectra of three samples $\mathrm{Cu}_{3}\left[\mathrm{Co}(\mathrm{CN})_{6}\right]_{2}$, $\mathrm{Cu}_{3}\left[\mathrm{Fe}(\mathrm{CN})_{6}\right]_{2}$ and $\mathrm{Cu}_{2}\left[\mathrm{Fe}(\mathrm{CN})_{6}\right]$ (Table I, (e),(j),(r)), together with the references spectra of $\mathrm{CuO}$ and $\mathrm{Cu}_{2} \mathrm{O}$. All the sample spectra are similar to the spectra of $\mathrm{CuO}$.

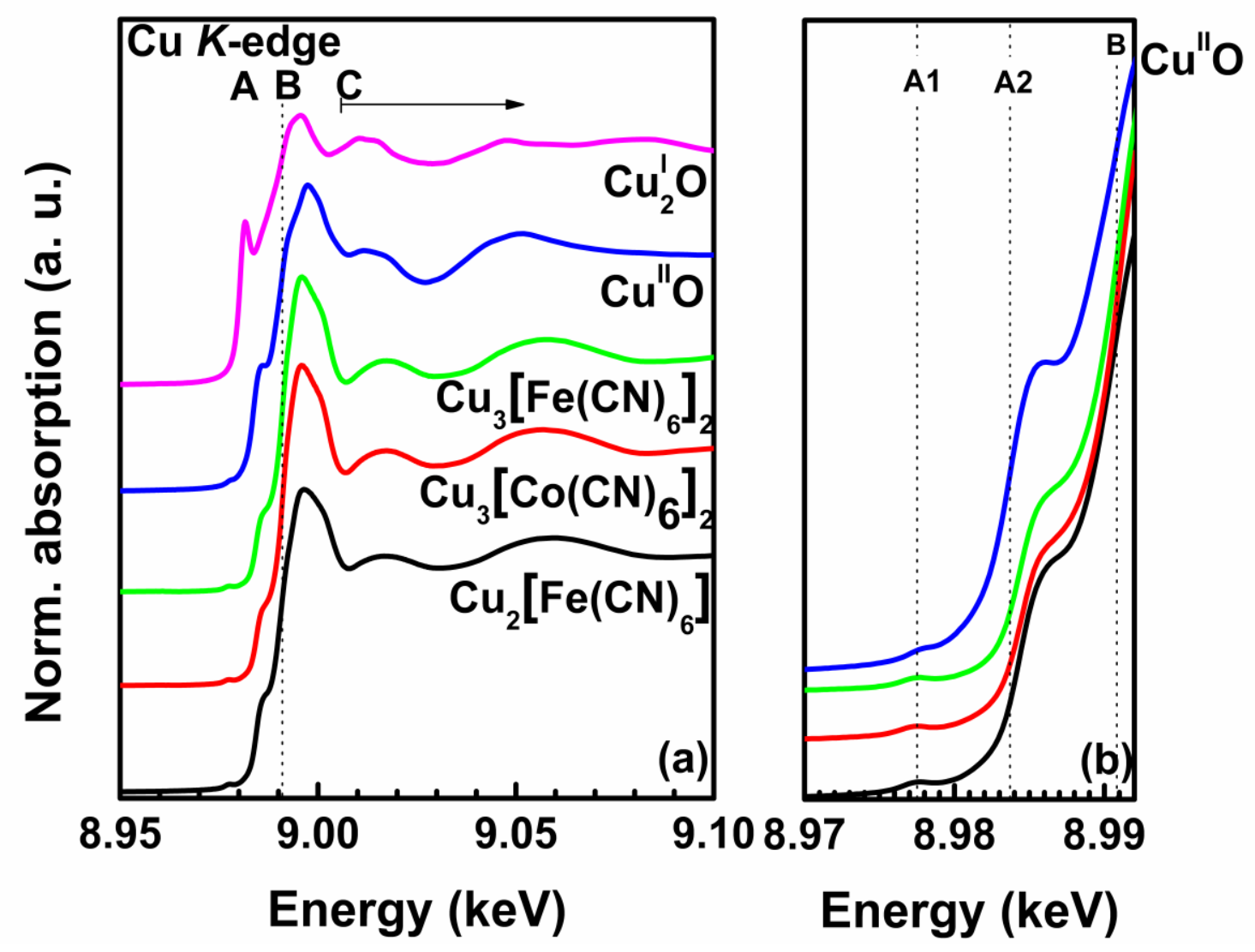

FIG. 13. (a) $\mathrm{Cu} K$-edge XANES for the Prussian Blue analogs containing $\mathrm{Cu}$, samples (e), (j), and ( $r$ ), along with that of the reference compounds $\mathrm{CuO}$ and $\mathrm{Cu}_{2} \mathrm{O}$. The energy scale is relative to the $\mathrm{Cu} K$-edge in metal $(8.979 \mathrm{keV})$. The dotted line indicates the edge positions. The details of the pre-edge regions of the XANES spectra are shown in (b).

As illustrated in the reference spectra of $\mathrm{CuO}$, pre-edge $(\mathrm{A})$ of divalent $\mathrm{Cu}$ contains a small resonance peak (A1) at $\sim 8.9775 \mathrm{keV}$ and a shoulder (A2) at $\sim 8.9837 \mathrm{keV}$. The pre-edge resonance peak is assigned to the $1 s \rightarrow 3 d$ electronic transition and has been observed in $\mathrm{Cu}(\mathrm{II})$ complexes by other researchers. ${ }^{28-36} \mathrm{In}$ the reference compound $\mathrm{CuO}, \mathrm{Cu}(\mathrm{II})$ is tetrahedrally coordinated with four oxygen atoms and this transition is allowed. However, in the samples, $\mathrm{Cu}$ atoms are 
octahedrally surrounded by six $\mathrm{N}$ atoms. This feature is also observed in the samples indicating the presence of $\mathrm{Cu}$ atoms in a distorted octahedral coordination. The second pre-edge feature (A2) is a shoulder which is observed for both the spectra of the model compound $\mathrm{CuO}$ and the spectra of the samples. This small resonance shoulder occurs due to $1 s \rightarrow 4 p_{z}$ transitions. $^{30,40}$

The inflection point right after the shoulder in the pre-edge region is chosen as the main edge (B) and it occurs at $8.9908 \mathrm{keV}$ for the $\mathrm{Cu}$ "O reference as well as for the samples. The main edge for the $\mathrm{Cu}(\mathrm{I})$ model spectra occurs at $8.9909 \mathrm{keV}$. The XANES pre-edge feature of the $\mathrm{Cu}_{2} \mathrm{O}$ contains a typical sharp resonance peak at $\sim 8.9841 \mathrm{keV}$ which is assigned to $1 s \rightarrow 4 p_{x, y}$ transition. ${ }^{36}$ This implies the presence of divalent $\mathrm{Cu}$ in the samples. The post edge features for the sample spectra are very similar and matches well with the spectra of $\mathrm{CuO}$. As can be seen, the shape of the Cu K-edge XANES spectra for the three compounds $\mathrm{Cu}_{3}\left[\mathrm{Co}(\mathrm{CN})_{6}\right]_{2}$, $\mathrm{Cu}_{3}\left[\mathrm{Fe}(\mathrm{CN})_{6}\right]_{2}$ and $\mathrm{Cu}_{2}\left[\mathrm{Fe}(\mathrm{CN})_{6}\right]$ are almost identical implying similar local octahedral coordination geometry.

The pre-edge features, edge position and shape of the edge for all three sample spectra match closely with the reference spectra of $\mathrm{CuO}$ indicating the presence of $\mathrm{Cu}(\mathrm{II})$ in the samples.

\section{Conclusion}

We have measured and analyzed the $\mathrm{Cr}, \mathrm{Mn}, \mathrm{Fe}, \mathrm{Co}, \mathrm{Ni}, \mathrm{Cu}$ K-edge XANES spectra of a series of Prussian Blue analogs - hexacyanometalates(III) $\mathrm{M}^{\prime \prime}{ }_{3}\left[\mathrm{~A}^{\prime \prime \prime}(\mathrm{CN})_{6}\right]_{2} \cdot \mathrm{nH}_{2} \mathrm{O}(\mathrm{M}=\mathrm{Mn}, \mathrm{Fe}, \mathrm{Co}, \mathrm{Ni}, \mathrm{Cu}, \mathrm{Zn} ; \mathrm{A}=\mathrm{Co}, \mathrm{Fe}, \mathrm{Cr} ; n=$ no. of water molecules present), hexacyanoferrates(II) $\left.M_{2}^{\prime \prime}{ }_{2} \mathrm{Fe}^{\prime \prime}(\mathrm{CN})_{6}\right]_{2} \cdot \mathrm{nH}_{2} \mathrm{O}(\mathrm{M}=\mathrm{Mn}, \mathrm{Co}, \mathrm{Ni}, \mathrm{Cu}$, $\mathrm{Zn})$ and mixed hexacyanometalates(III) $\left(\mathrm{Fe}_{1-x} \mathrm{Co}_{x}\right)_{3}\left[B^{\prime \prime \prime}(\mathrm{CN})_{6}\right]_{2} \cdot n \mathrm{H}_{2} \mathrm{O}(x=0.25,0.5$, $0.75 ; B=C o, F e)$. All the transition metals were found to be either in a single oxidation state or in mixed oxidation states. Table II and III show a summary of the oxidation states (OS) of the transition metals for all the studied Prussian Blue analogs as obtained from our XANES measurements and as discussed in the previous sections. The thermal expansion coefficient for the compounds $\alpha$ is listed as well. Recently, we published a systematic investigation of the magnetic properties 
of $\mathrm{M}^{\prime \prime}{ }_{3}\left[\mathrm{~A}^{\prime \prime \prime}(\mathrm{CN})_{6}\right]_{2} \cdot n \mathrm{H}_{2} \mathrm{O}(\mathrm{M}=\mathrm{Mn}, \mathrm{Co}, \mathrm{Ni}, \mathrm{Cu} ; \mathrm{A}=\mathrm{Co}, \mathrm{Fe}, \mathrm{Cr}) .{ }^{37}$ We find that the results can be interpreted in reasonable agreement with the here determined valences leading to particular configurations of high- and low-spin states. XANES measurements deliver valuable information not only to the oxidation state of the metal ion but also to the spin state as observed for the iron(II) complexes.

We could not discover a direct dependence of the thermal expansion of the PBAs on the oxidation state of the transition metal ions (Table II). We previously observed ${ }^{3}$ that the hexacyanocobaltates(III) show negative thermal expansion. The coefficient for thermal expansion correlates inversely with the Irving-Williams series ${ }^{42}$ for transition metal complex stability $(\mathrm{Mn}(\mathrm{II})<\mathrm{Fe}(\mathrm{II})<\mathrm{Co}(\mathrm{II})<\mathrm{Ni}(\mathrm{II})<\mathrm{Cu}(\mathrm{II})>\mathrm{Zn}(\mathrm{II}))$. All complexes have the transition metals in the divalent oxidation state except for the iron(II) hexacyanocobaltate(III) which contains besides high-spin $\mathrm{Fe}(\mathrm{II})$ also Fe(III). Comparing this compound to $\mathrm{Fe}^{\mathrm{III}}\left[\mathrm{Co}^{\prime \prime \prime}(\mathrm{CN})_{6}\right]^{43}$ crystallizing in the same space group, we find that our compound containing a mixture of $\mathrm{Fe}(\mathrm{hs}, \mathrm{II})$ and $\mathrm{Fe}(\mathrm{III})$ has a much larger negative thermal expansion of $\alpha=-39^{*} 10^{-6} \mathrm{~K}^{-1}$ than $\mathrm{Fe}^{\prime \prime \prime}\left[\mathrm{Co}^{\prime \prime \prime}(\mathrm{CN})_{6}\right]$ with $\alpha=-$ $1.47^{\star} 10^{-6} \mathrm{~K}^{-1}$.

The hexacyanoferrates(III) and hexacyanoferrates(II) exhibit thermal expansion behavior that is non-consistent with the Irving-Williams series. All the transition metal ions $\mathrm{M}(\mathrm{II})$ are in the expected divalent oxidation state except for the cobalt compounds, $\mathrm{Co}_{3}\left[\mathrm{Fe}^{\prime \prime I}(\mathrm{CN})_{6}\right]_{2}$ and $\mathrm{Co}_{2}\left[\mathrm{Fe}^{\prime \prime}(\mathrm{CN})_{6}\right]_{2}$, which contain $\mathrm{Co}(\mathrm{III})$ as well as $\mathrm{Co}(\mathrm{II})$. The hexacyanoferates(III) show decreasing positive thermal expansion for $\mathrm{Mn}(\mathrm{II})>\mathrm{Co}(\mathrm{II})>\mathrm{Ni}(\mathrm{II})>\mathrm{Cu}(\mathrm{II})>\mathrm{Zn}(\mathrm{II})$ while the hexacyanoferrates(II) exhibit positive thermal expansion with a coefficient of roughly $+20^{\star} 10^{-6} \mathrm{~K}^{-1}$ for all investigated compounds with the exception of the significantly larger value for $\mathrm{Zn}(\mathrm{II})$. The hexacyanochromates(III) vary strongly in the thermal expansion coefficient as well as in the oxidation states of the transition metal ions.

For the bimetallic hexacyanocobaltates(III) and hexacyanoferrates(III) (Table III), a trend can be discussed. While the hexacyanocobaltates(III) have a maximum of the thermal expansion coefficient at $\alpha=0$ with a ratio of Fe:Co $=1: 1(x=0.5)$, the hexacyanoferrates(III) have a minimum at $\alpha=-6$ for the Fe:Co ratio of $1: 1(x=0.5)$. In the former case high-spin $\mathrm{Fe}(\mathrm{II})$ is present and the thermal expansion for $\mathrm{x}<0.5$ and 
$x>0.5$ is negative, while in the later low-spin $\mathrm{Fe}(\mathrm{II})$ is present and the thermal expansion is slightly positive for $x<0.5$ and $x>0.5$.

A direct dependence of the thermal expansion on oxidation or spin state could not be found even though trends are observable. For example, it seems from comparison of $\mathrm{Fe}_{3}{ }_{3}\left[\mathrm{Co}^{\prime \prime \prime}(\mathrm{CN})_{6}\right]_{2}$ to $\mathrm{Fe}^{\prime \prime \prime}\left[\mathrm{Co}^{\prime \prime \prime}(\mathrm{CN})_{6}\right]^{43}$ and to the series of $\left(\mathrm{Fe}_{1-\mathrm{x}} \mathrm{Co}_{\mathrm{x}}\right)^{\prime \prime}{ }_{3}\left[\mathrm{Co}^{\mathrm{III}}(\mathrm{CN})_{6}\right]_{2}$ and $\left(\mathrm{Fe}_{1-\mathrm{x}} \mathrm{Co}_{\mathrm{x}}\right)_{3}{ }_{3}\left[\mathrm{Fe}^{\mathrm{III}}(\mathrm{CN})_{6}\right]_{2}$ compounds that $\mathrm{Fe}(\mathrm{II})$ and $\mathrm{Co}(\mathrm{II})$ ions in combination with hexacyanocobaltate(III) are preferable to $\mathrm{Fe}(\mathrm{III})$ for negative thermal expansion. A careful synthesis of a series of mixed divalent and trivalent hexacyanocobaltates(III) and hexacyanoferrates(III) with $\mathrm{M}=\mathrm{Fe}, \mathrm{Co}$ and a more thorough study of the hexacyanochromates(III) might help shed light on the connection between oxidation states, spin states and d-orbital occupancy and consequently the bonding between the transition metals and the $\mathrm{CN}$ ligand thus the resulting flexibility of the lattice to undergo negative thermal expansion.

TABLE II. Summary of oxidation states (OS) of the transition metals in the studied PB analogs as obtained from the analysis of the metal k-edge XANES spectral analysis and their thermal expansion coefficient $\alpha$ (units of $10^{-6} \mathrm{~K}^{-1}$ ). ${ }^{3}$

\begin{tabular}{|c|c|c|c|c|c|c|c|c|}
\hline \multirow[b]{2}{*}{$\mathrm{M}$} & \multicolumn{2}{|c|}{$\mathrm{M}_{3}^{\prime \prime}\left[\mathrm{Co}^{\prime \prime \prime}(\mathrm{CN})_{6}\right]_{2}$} & \multicolumn{2}{|c|}{$\mathrm{M}_{3}^{\mathrm{II}}\left[\mathrm{Fe}^{\mathrm{III}}(\mathrm{CN})_{6}\right]_{2}$} & \multicolumn{2}{|c|}{$\mathrm{M}_{2}^{\prime \prime}\left[\mathrm{Fe}^{\prime \prime}(\mathrm{CN})_{6}\right]$} & \multicolumn{2}{|c|}{$\mathrm{M}_{3}^{\prime \prime}\left[\mathrm{Cr}^{\prime \prime \prime}(\mathrm{CN})_{6}\right]_{2}$} \\
\hline & OS & $\alpha$ & OS & $\alpha$ & OS & $\alpha$ & OS & $\alpha$ \\
\hline $\mathrm{Mn}$ & $\begin{array}{l}\mathrm{Mn}^{\prime \prime} \\
\mathrm{Co}\end{array}$ & -48 & $\begin{array}{l}\mathrm{Mn}^{I I} \\
\mathrm{Fe}^{\mathrm{III}}\end{array}$ & +48 & $\begin{array}{l}\mathrm{Mn}^{I I} \\
\mathrm{Fe}^{\prime \prime}\end{array}$ & +20 & $\begin{array}{l}b \\
b\end{array}$ & $B$ \\
\hline $\mathrm{Fe}$ & $\begin{array}{r}\mathrm{Fe}^{\mathrm{hs}, \mathrm{II}} / \mathrm{Fe}^{\mathrm{III}} \\
\mathrm{Co}{ }^{\mathrm{III}}\end{array}$ & -39 & $\begin{array}{l}b \\
b\end{array}$ & $b$ & $\begin{array}{l}b \\
b\end{array}$ & $b$ & $\begin{array}{r}\mathrm{Fe}^{I I} / \mathrm{Fe}^{\mathrm{III}} \\
\mathrm{Cr}^{\mathrm{III}}\end{array}$ & -5 \\
\hline Co & $\begin{array}{c}\mathrm{Co} \\
\mathrm{Co} \\
\mathrm{ClII}\end{array}$ & -36 & $\begin{array}{c}\mathrm{Co} / \mathrm{Co} \\
\mathrm{Fe}^{\mathrm{III}}\end{array}$ & +8 & $\begin{array}{c}\mathrm{Co}^{\prime \prime} / \mathrm{Co}^{\mathrm{III}} \\
\mathrm{Fe}^{\prime \prime}\end{array}$ & +20 & $\begin{array}{c}\mathrm{Co} / \mathrm{Co} \\
\mathrm{Cr}^{\prime \prime I I}\end{array}$ & +59 \\
\hline $\mathrm{Ni}$ & $\begin{array}{c}\mathrm{Ni}^{I I} \\
\mathrm{Co}^{\mathrm{III}}\end{array}$ & -30 & $\begin{array}{c}\mathrm{Ni}^{\mathrm{II}} \\
\mathrm{Fe}^{\mathrm{III}}\end{array}$ & +6 & $\begin{array}{l}\mathrm{Ni}^{\mathrm{II}} \\
\mathrm{Fe}^{\mathrm{II}}\end{array}$ & +20 & $\mathrm{Ni}^{\mathrm{III}}$ & +10 \\
\hline $\mathrm{Cu}$ & $\begin{array}{l}\mathrm{Cu}^{11} \\
\mathrm{Co}^{\mathrm{III}}\end{array}$ & -20 & $\begin{array}{l}\mathrm{Cu}^{I I} \\
\mathrm{Fe}^{\text {III }}\end{array}$ & -20 & $\begin{array}{l}\mathrm{Cu}^{I I} \\
\mathrm{Fe}^{\prime \prime}\end{array}$ & +20 & $\begin{array}{l}b \\
b \\
\end{array}$ & $b$ \\
\hline $\mathrm{Zn}$ & $\begin{array}{r}a \\
\text { Co }\end{array}$ & -34 & $\mathrm{Fe}^{a}$ & -40 & $\mathrm{Fe}^{\mathrm{a}}$ & +43 & $\begin{array}{l}b \\
b\end{array}$ & $b$ \\
\hline
\end{tabular}

TABLE III. Oxidation state (OS) of Iron (Fe) and Cobalt (Co) for the bimetallic PB analogs as obtained from the analysis of Fe and Co K-edge XANES spectra as well as the thermal expansion coefficient $\alpha$. 


\begin{tabular}{|c|c|c|c|c|}
\hline Compound & $\mathrm{M}$ & Bimetallic PB analogs & OS & $\alpha\left[10^{-6} \mathrm{~K}^{-1}\right]$ \\
\hline \multirow{5}{*}{$\begin{array}{l}\left(\mathrm{Fe}_{1-\mathrm{x}} \mathrm{Co}_{\mathrm{x}}\right)_{3} \\
{\left[\mathrm{Co}(\mathrm{CN})_{6}\right]_{2}}\end{array}$} & $x=0$ & $(\mathrm{Fe})_{3}\left[\mathrm{Co}(\mathrm{CN})_{6}\right]_{2}$ & $\begin{array}{l}\text { Co III, } \\
\mathrm{Fe}^{\mathrm{hs}, \mathrm{II}}, \mathrm{Fe}^{\mathrm{III}}\end{array}$ & -39 \\
\hline & $x=0.25$ & $\left(\mathrm{Fe}_{0.75} \mathrm{Co}_{0.25}\right)_{3}\left[\mathrm{Co}(\mathrm{CN})_{6}\right]_{2}$ & $\begin{array}{l}\text { Co", Coo"', } \\
\mathrm{Fe}^{\mathrm{hs}, \mathrm{II}}, \mathrm{Fe} \mathrm{e}^{\mathrm{III}}\end{array}$ & -20 \\
\hline & $x=0.5$ & $\left(\mathrm{Fe}_{0.50} \mathrm{Co}_{0.50}\right)_{3}\left[\mathrm{Co}(\mathrm{CN})_{6}\right]_{2}$ & $\begin{array}{l}\text { Co", Col'I" } \\
\mathrm{Fe}^{\mathrm{hs}, \mathrm{II}}, \mathrm{Fe}^{\mathrm{ill}}\end{array}$ & 0 \\
\hline & $x=0.75$ & $\left(\mathrm{Fe}_{0.25} \mathrm{Co}_{0.75}\right)_{3}\left[\mathrm{Co}(\mathrm{CN})_{6}\right]_{2}$ & $\begin{array}{l}\text { Co", } \mathrm{Co}^{\prime \prime \prime}, \\
\mathrm{Fe}^{\mathrm{hs}, \mathrm{Il}}, \mathrm{Fe}^{\mathrm{III}}\end{array}$ & -19 \\
\hline & $x=1$ & $(\mathrm{Co})_{3}\left[\mathrm{Co}(\mathrm{CN})_{6}\right]_{2}$ & Co", Co"lI' & -36 \\
\hline \multirow{5}{*}{$\begin{array}{l}\left(\mathrm{Fe} e_{1-x} \mathrm{Co}_{x}\right)_{3} \\
{\left[\mathrm{Fe}(\mathrm{CN})_{6}\right]_{2}}\end{array}$} & $x=0$ & $(\mathrm{Fe})_{3}\left[\mathrm{Fe}(\mathrm{CN})_{6}\right]_{2}$ & $\begin{array}{l}a \\
a\end{array}$ & A \\
\hline & $x=0.25$ & $\left(\mathrm{Fe}_{0.75} \mathrm{Co}_{0.25}\right)_{3}\left[\mathrm{Fe}(\mathrm{CN})_{6}\right]_{2}$ & $\begin{array}{l}\mathrm{Co}^{\prime \prime}, \mathrm{Co}^{\mathrm{III}}, \\
\mathrm{Fe}^{\mathrm{Is}, \|}, \mathrm{Fe}^{\mathrm{III}}\end{array}$ & +10 \\
\hline & $x=0.5$ & $\left(\mathrm{Fe}_{0.50} \mathrm{Co}_{0.50}\right)_{3}\left[\mathrm{Fe}(\mathrm{CN})_{6}\right]_{2}$ & $\begin{array}{l}\mathrm{Co}^{\prime \prime}, \mathrm{Co}^{\mathrm{III}}, \\
\mathrm{Fe}^{\mathrm{Is}, \|}, \mathrm{Fe}^{\mathrm{III}}\end{array}$ & -6 \\
\hline & $x=0.75$ & $\left(\mathrm{Fe}_{0.25} \mathrm{Co}_{0.75}\right)_{3}\left[\mathrm{Fe}(\mathrm{CN})_{6}\right]_{2}$ & $\begin{array}{l}\mathrm{Co}^{\prime \prime \prime}, \mathrm{Co}{ }^{\mathrm{III}} \\
\mathrm{Fe}^{\mathrm{Is}, \mathrm{l}}, \mathrm{Fe} \mathrm{Fe}^{\prime \prime \prime \prime}\end{array}$ & +2 \\
\hline & $x=1$ & $(\mathrm{Co})_{3}\left[\mathrm{Fe}(\mathrm{CN})_{6}\right]_{2}$ & $\begin{array}{l}\mathrm{Co}^{\prime \prime \prime}, \mathrm{Co}^{\mathrm{III}} \\
\mathrm{Fe}^{\mathrm{III}}\end{array}$ & +8 \\
\hline
\end{tabular}

${ }^{\mathrm{a}}$ Compounds which are not studied

\section{ACKNOWLEDGMENTS}

This work has benefitted from the use of Advanced Photon Source at Argonne National Laboratory which is supported by the U.S. Department of Energy, Office of Science, Office of Basic Energy Sciences, under Contract No. DE-AC02$06 \mathrm{CH} 11357$. We would like to thank Dr. Trudy Bolin for her help with experiments at the 9-BM-B beamline at Advanced Photon Source. This research work has been supported by Department of Energy's (DOE) Office of Basic Energy Sciences and has made use of Manuel Lujan, Jr. Neutron Scattering Center at Los Alamos National Laboratory which is funded by DOE Office of Basic Energy Sciences. Los Alamos National Laboratory is operated by Los Alamos National Security, LLC, under DOE Contract DE-AC52-06NA2539 


\section{References}

${ }^{1}$ T. Matsuda, J. E. Kim, K. Ohoyama, and Y. Moritomo, Physical Review B 79, 172302 (2009).

${ }^{2}$ K. W. Chapman, P. J. Chupas, and C. J. Kepert, Journal of the American Chemical Society 128, 7009 (2006).

${ }^{3}$ S. Adak, L. L. Daemen, M. Hartl, D. Williams, J. Summerhill, and H. Nakotte, Journal of Solid State Chem. 184, 2854 (2011).

${ }^{4}$ T. Yokoyama, T. Ohta, O. Sato, and K. Hashimoto, Physical Review B 58, 8257 (1998).

${ }^{5}$ A. Bleuzen, C. Lomenech, V. Escax, F. Villain, F. Varret, C. C. D. Moulin, and M. Verdaguer, Journal of the American Chemical Society 122, 6648 (2000).

${ }^{6}$ T. Ressler, J. Synch. Rad. 5, 118 (1998).

${ }^{7}$ S. Bajt, S. B. Clark, S. R. Sutton, M. L. Rivers, and J. V. Smith, Anal. Chem. 65, 1800 (1993).

${ }^{8}$ L. F. Mattheiss, Phys. Rev. B 5, 290 (1972).

${ }^{9}$ A. Manceau and L. Charlet, J. Colloid Interface Sci. 148, 425 (1992).

${ }^{10}$ M. Tromp, J. Moulin, G. Reid, and J. Evans, AIP Conf. Proc. 882, 699 (2006).

${ }^{11}$ M. Giorgetti, S. Della Longa, M. Benfatto, J. Phys: Conf. Series 190, 012145 (2009)

${ }^{12}$ I. Bonhoure, C. D. Auwer, C. C. Moulin, P. Moisy, J-C Berthet, C. Madic, Can. J. Chem. 78, 1305 (2000).

${ }^{13}$ F. Farges, Phys. Rev. B 71, 155109 (2005).

${ }^{14}$ G. Drager, Th. Kirner, S. Bocharov, and C. C. Kao, J. Synchrotron Radiat. 8, 398 (2001).

${ }^{15}$ P. Glatzel, U. Bergmann, J. Yano, H. Visser, J. H. Robblee, W. Gu, F. de Groot, G.

Christou, V. L. Pecoraro, S. P. Cramer, and V. K. Yachandra, J. Am. Chem. Soc. 136, 9946 (2004).

${ }^{16} \mathrm{~N}$. Kosugi, T. Yokoyama, H. Kuroda, Chem. phys. 104, 449 (1986).

${ }^{17}$ T. Yokoyama, T. Ohta, O. Sato, K. Hasimoto, Phys. Rev. B 58, 8257 (1998).

${ }^{18}$ A. Bianconi, M. Dell'Ariccia, P. J. Durham, J. B. Pendry, Phys. Rev. B 26, 6502 (1982).

${ }^{19}$ A. Bleuzen, C. Lomenech, V. Escax, F. Villain, F. Varret, C. C. Moulin, and M. Verdaguer, J. Am. Chem. Soc. 122, 6648 (2000).

${ }^{20}$ M. Sano, Inorg. Chem. 27, 4249 (1988).

${ }^{21}$ P. J. Kulesza, M. A. Malik, M. Berrettoni, M. Giorgetti, S. Zamponi, R. Schmidt, and R. Marassi, J. Phys. Chem. B 102, 1870 (1998).

${ }^{22}$ V. Briois, C. Cartier, M. Momenteau, P. Maillard, J. Zarembowitch, E. Dartyge, A. Fontaine, G. Tourillon, P. Thuéry, and M. J. Verdaguer, J. Chim. Phys. 86, 1623 (1989).

${ }^{23} J$. Shearer and P. Soh, J. Inorg. Biochem. 101, 370 (2007)

${ }^{24}$ T. H. Gardner, J. J. Spivey, E. L. Kugler, A. Campos, J. C. Hissam, A. D. Roy, J. Phys. 
Chem. C 114, 7888 (2010).

${ }^{25}$ P. E. Carrington, F. Al-Mjeni, M. A. Zoroddu, M. Costa, and M. J. Maroney, Environ.

Health Perspective 110, 705 (2002).

${ }^{26}$ T. Yoshida, T. Tanaka, H. Yoshida, T. Funabiki, and S. Yoshida, J. Phys. Chem. 100, 2302 (1996).

${ }^{27}$ L. Campbell, S. Tanaka, and S. Mukamel, Chem. Phys. 299, 225 (2004).

${ }^{28}$ K. Shimizu, H. Maeshima, H. Yoshida, A. Satsuma, and T. Hattori, Phys. Chem. Chem. Phys. 3, 862 (2001).

${ }^{29}$ L.S. Kau, K. O. Hodgson, and E.I. Solomon, J. Am. Chem.. Soc. 111, 7103 (1989).

${ }^{30}$ N. Kosugi, T. Okoyama, K. Asakura, H. Kuroda, Chem. Phys. 91, 249 (1984).

${ }^{31}$ L. Andrini, C. M. Chanquía, G. A. Eimer, and F. G. Requejo, LNLS Activity Report (2009).

${ }^{32}$ R. K. Selvan, V. Krishnan, C. O. Augustin, H. Bertagnolli, C. S. Kim, and A. Gedanken, Chem. Mater. 20, 429 (2008).

${ }^{33}$ A Gaur, B. D. Shrivastava, S. K. Joshi, Journal of Physics: Conference Series 190, 012084 (2009)

${ }^{34}$ M Sano, S. Komorita, and H. Yamatera, Inorganic Chemistry 31 (3), 459 (1992)

${ }^{35}$ K. B. Garg, R. K. Singhal, K. V. R. Rao, U. Chandra, H. S. Chauhan, J. Singh, K. S. Jerath, and D. C. Jain, Phys. Stat. Sol. (b) 147, 343 (1988).

${ }^{36}$ J. Rothe, J. Hormes, H. Bönnemann, W. Brijoux, and K. Siepen, J. Am. Chem. Soc. 120, 6019 (1998).

${ }^{37}$ H. Nakotte, M. Shrestha, S. Adak, M. Boergert, V.S. Zapf, N. Harrison, G. King, and L.L.

Daemen, Journal of Science - Advanced Materials and Devices. 1, 113 (2016).

${ }^{38}$ D.J. Rudd, C.R. Goldsmith, A.P.Cole, T.D.P. Stack, K.O. Hodgson, B. Hedman, Inorg. Chem. 44, 1121 (2005).

${ }^{39}$ E. Reguaer, J. Fernandez-Bertran, A. Dago, C. Diaz, Hyper. Int. 73, 295 (1992).

${ }^{40}$ Kosugi, N.; Yokoyama, T.; Asakura, K.; Kuroda, H. Chem. Phys. 91, 249-256 (1984).

${ }^{41}$ Larson A.C., and R.B. von Dreele, General Structure Analysis System (GSAS), Los

Alamos National Laboratory Report No. LAUR 86-748 (2000).

${ }^{42}$ H. Irving, R.J.P. Williams, J. Chem. Soc. 637, 3192 (1953).

${ }^{43}$ S. Margadonna, K. Prassides, A.N. Fitch, JACS 126, 15390-15391(2004) 